\title{
THE STRUCTURE OF SYMBOLIZING IN THE NOVEL "TESTIMONY OF WARTIME" IN THE LIGHT OF CHARLES SANDERS PIERCE'S THEORY
}

\author{
Khalid Sulaiman Muhanna ALKINDI ${ }^{1}$
}

\section{Istanbul / Türkiye}

p. $136-151$

Received: 05/11/2021

Accepted: $15 / 12 / 2021$

Published: 01/01/2022

This article has been scanned ! iThenticat No plagiarism detected

\begin{abstract}
:
Symbolizing means the transition from the significance of the phonetic, morphological and syntactic units to the implicated meaning arising from the relations and common knowledge between the interlocutors and the circumstances surrounding them at the moment of the speech. The study seeks to present the symbolizing mechanism presented by Charles Sanders Peirce in the theory of signs, test the value of this mechanism and search for the linguistic structures responsible for symbolizing in the novel "Testimony from Wartime.
\end{abstract}

Key words: Symbolizing, Bitcoin, Charles Sanders Pierce's Theory, Testimony of Wartime.

http://dx.doi.org/10.47832/2717-8293.15.10

1 (iD) Dr. , Sultan Qaboos University, Sultanate of Oman, abuqasimkindi@ gmail.com, https://orcid.org/0000-0003-1349$\underline{4460}$ 


\section{بُنَى الترميز في رواية "شهادة من زمن الحرب" في ضوء نظرية تشارلز ساندرس بيرس}

\section{خالد بن سليمان بن مهنا الكندي 2}

الملخص:

يعني الترميز الانتقال من دلالة الوحدات الصوتية والصرفية والتركيبة إلى المعنى الاقتضائي الناشئ من العلاقات والمعرفة المشتركة بين المتخاطبين والظروف المحيطة بهم لحظة الخطاب. وتسعى الدراسة إلى تقديم آلية الترميز التي قدّمها تشارلز ساندرس بيرس في نظرية العلامات، واختبار قيمة هذه الآلية والبحث عن البنى اللغوية المسؤولة الترميز في رواية "شاهد من زمن الحرب".

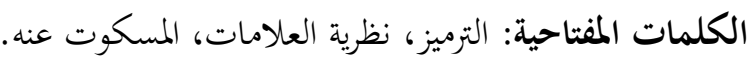

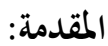

يفرق الناقد والمفكر الفرنسي تزفيتان تودوروف بين العلامة والرمز، فيجعل العلامة دالَّا لغويَّ يَفْهَمُ منه المتلقي الدلالة

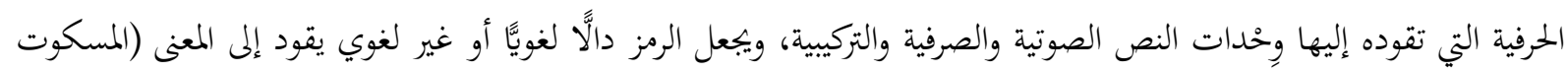

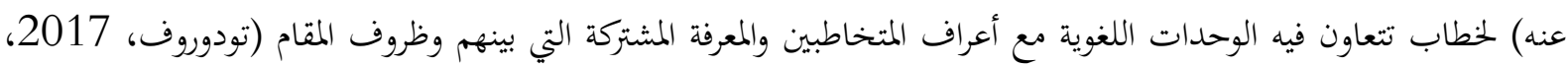

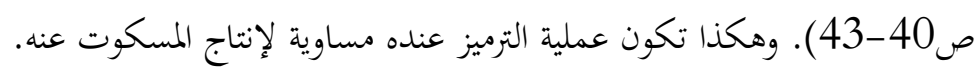
وقد اجتهد مؤسس الفلسفة الذرائعية الفيلسوف الأمريكي تشارلز ساندر بيرس (1839-1914م) في الدعوة إلى علم

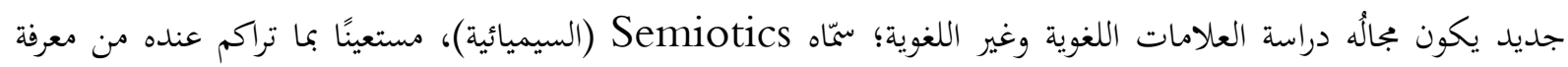

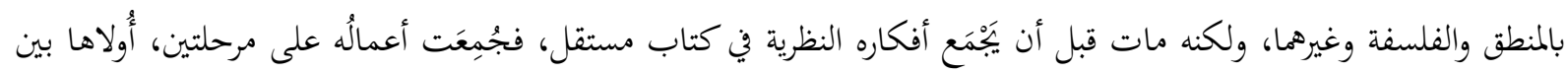
عامَي 1931-1935م، وأُخْراها عام 1958.

وغايتنا في هذه الدراسة البحث في نظرية بيرس عن البنى المسؤولة عن صناعة الترميز بمفهومه الذي قدّمه تزفيتان تودوروف،

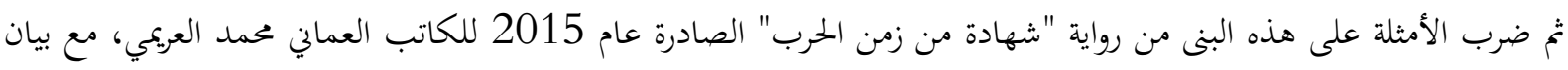
القيمة الفنية لهذه البنى الرمزية. 


\section{المبحث الأول: مضمون رواية "شهادة من زمن الحرب":}

أُخِخَ محتوى الرواية من اعترافات شاب عُماني اسمه ماجد عاش أحداث سقوط كابل على يد حلف الناتو، وأدلى بشهادته

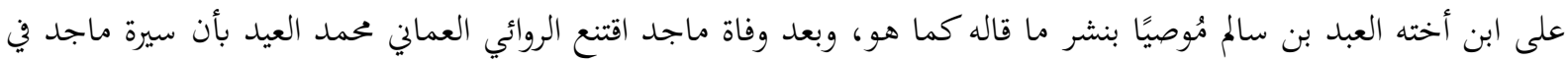

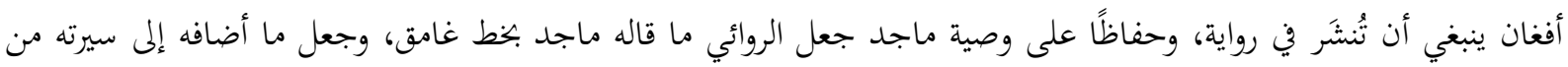
تفصيلات حقيقية أخذها من العبد بن سالم أو تصوّرها بخياله بخط مائل.

ماجد من أسرة مَشْيْة في ولاية صُور في عُمان، هاجر إلى لندن ليدرس في إحدى جامعاما؛ لكنه انغمس في مراقص

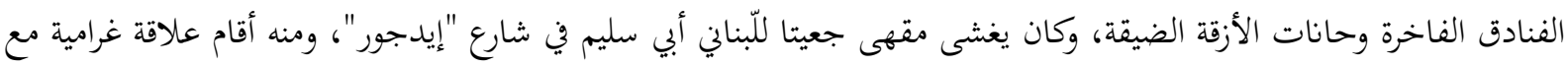

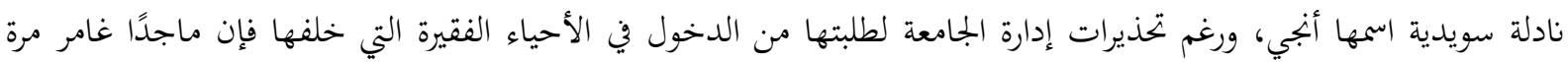

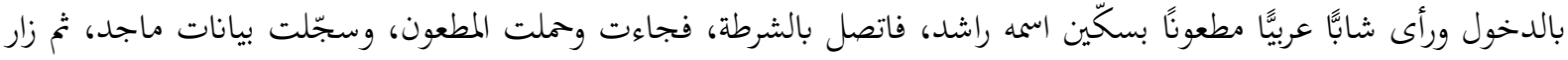

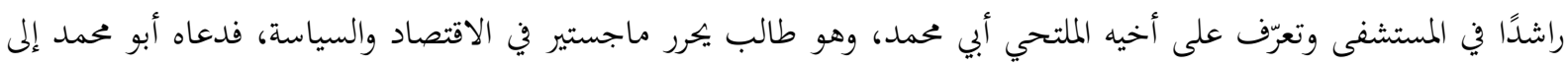

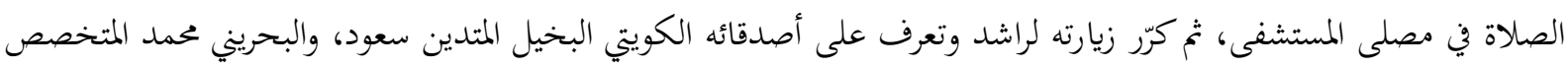
في الإنجليزية، والفلسسطيني ياسين المتخصص في الترجمة، ثم صار يزورهم في الشقة وأدرك تشدّد سعود ودماثة ياسين.

ياسين يعرف لغة الأوردو لأن أمه باكستانية وُلِيدت في بريطانيا، وبحكم تعامله مع الهيئات الدبلوماسية عمل في وكالة

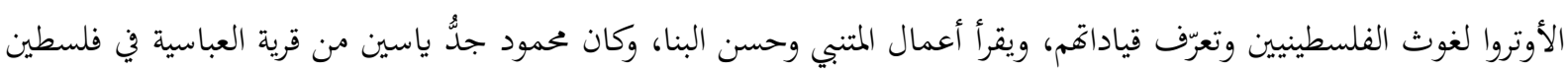
- التي سمّاها الاحتلال يهودا، ثم هرب من عصابة الهاغانة الصهيونية إلى جنوب لبنان، وحصل طه بن محمود على منحة دراسية

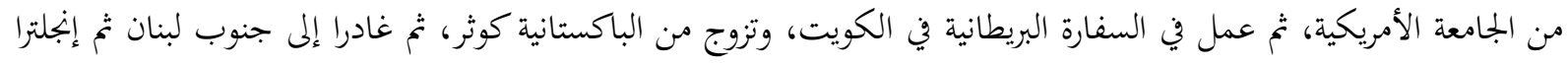

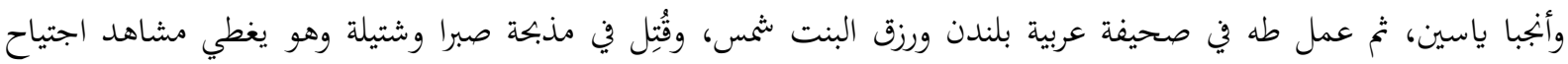

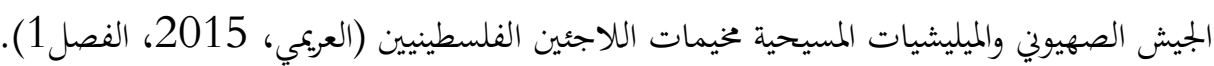
بعد اهيار البرجين في 11 سبتمبر 2001حرّضت أمريكا على الهجوم على العرب والمسلمين، وقررت غزو أفغانستان،

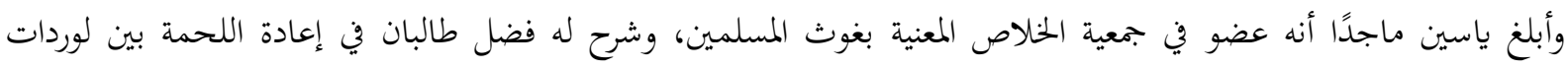
الحرب الأفغان بعد خروج الاتحاد السوفييتي، وبفضل ياسين ترك ماجد حياة الفحش، وشجّع ياسين بقية زملائه على دعم الجمعية، فوافق راشد على الإسهام بماله، واختار سعود أن يتصرف وحده، وتابع ماجد أخبار أفغانستان، وقرأ في إصدارات جمعية لئية الخلاص وقد أحضرها له ياسين؛ حتى اقتنع بالانضمام إلى الجمعية، وعادت به الذاكرة إلى بندقية "أم عشر" المعلقة في مجلس والدهاه الملقب بالشيخين؛ لأنه حصل على مشيخة القبيلة بعد وفاة والده وعلى مشيخة العلم من المدرسة الصولتية في مكة. وفي مطار

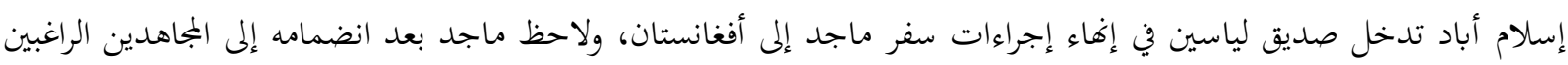

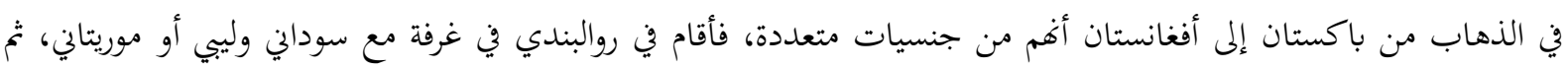

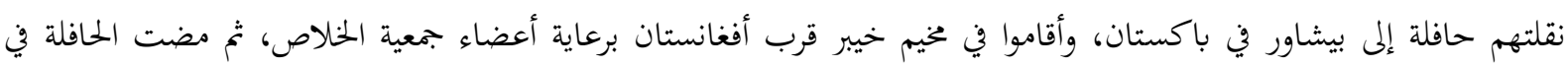
طرق وعرة شاهقة بين هندوكوش، وكان جوارَ ماجد صحفي بريطاني اسمه توم آشلاند، له معرفة واسعة بالإسلام لأنه درس في الأزهر، وغطّى انتفاضة الأقصى الثانية ضد شارون (السابق، الفصل 2هند).

في أفغانستان أصبح ماجد في جيش الخلاص لا في جمعية الخلاص، واختار له اسمًا جهاديًّ هو سعد العشيرة، وعلموا أنه

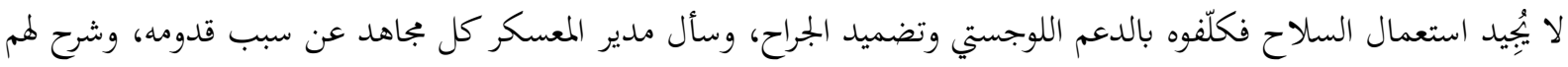
أن مهمة جيش الخلاص حماية قوافل الإمداد الباكستانية إلى طالبان من لوردات الحرب، وعلم ماجد أن الأفغان في الشمال

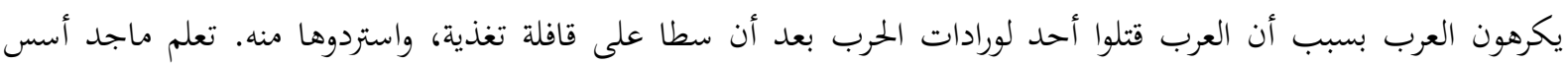


الإسعاف الأولي على يد الطبيب البوشناقي يوسف (أو كاظم الأسى في رمزه الجهادي)، وحدّثه عما فعله الصربيون بالتعاون مع

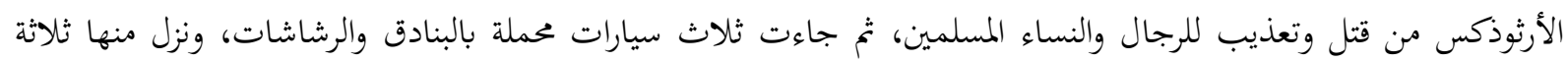

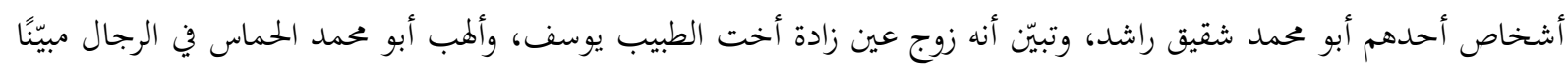

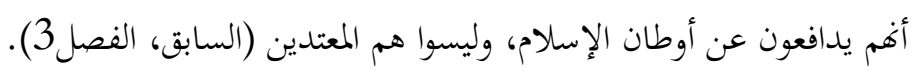
أبو محمد قائد كتيبة استطاعت تحرير نساء بوشناقيات منهن عين زادة أخت يوسف، ثم أسس جمعية لمساعدة الأسر المهجرة، وتزوج عين زادة بعد أن قتل الصربيون زوجها أمام عينيها لما ثار عليهم حين لمسوا بطنها الحامل، وأنجبت عين زئه زادة ابنها

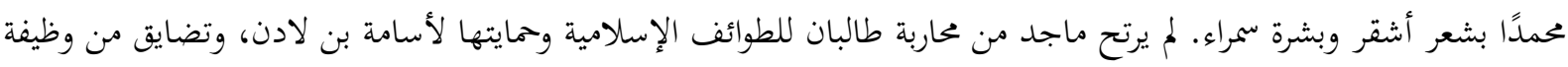

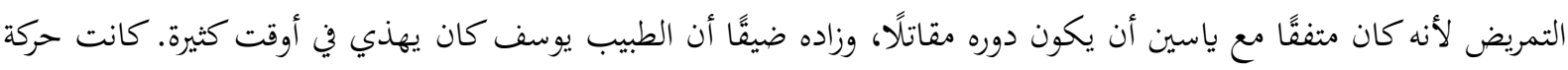

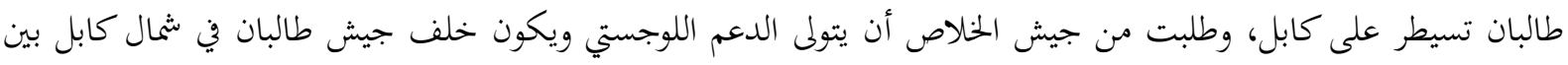

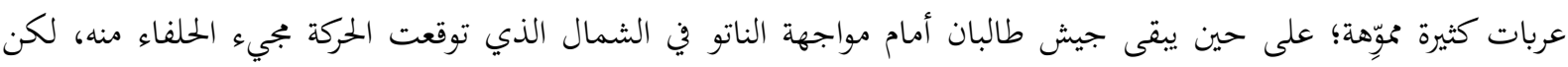

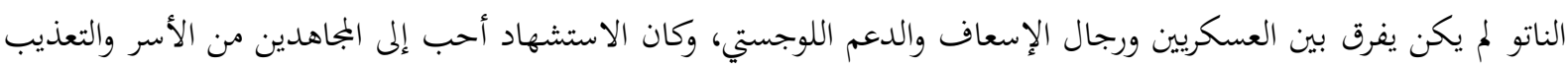

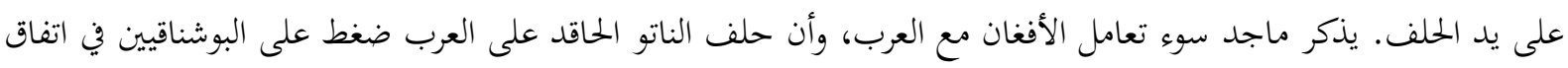
السلام مع صربيا على سحب جنسيات المجاهدين العرب، ما جعل هؤلاء العرب معلقين غير قادرين على البقاء في البوسنة

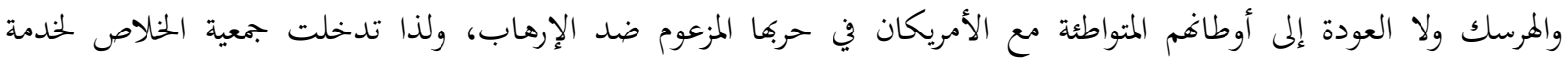

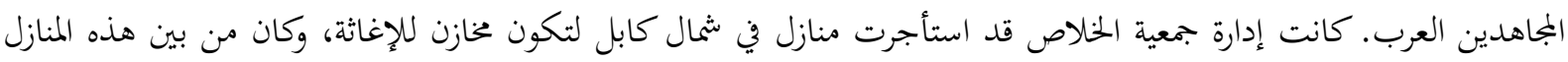

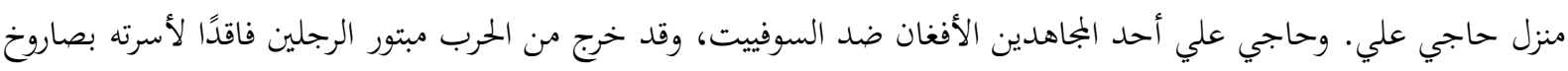

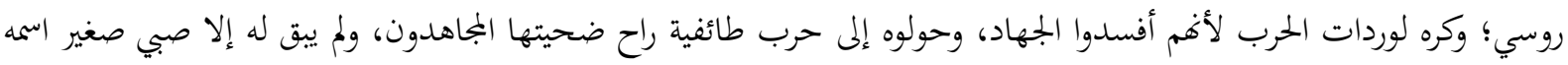

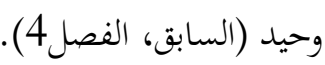

شنّت أمريكا هجومًا عنيفًا على مواقع طالبان والمدنيين، ودلّ وحيد ماجدًا وأصحابه على سرداب للهرب من القصف،

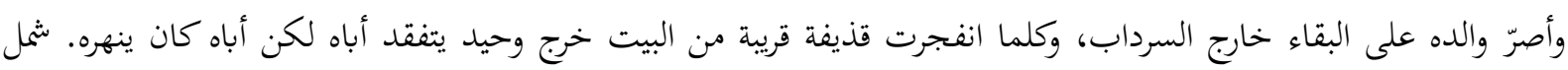

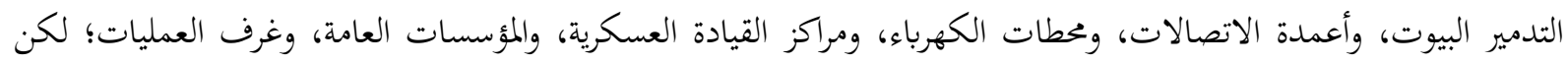

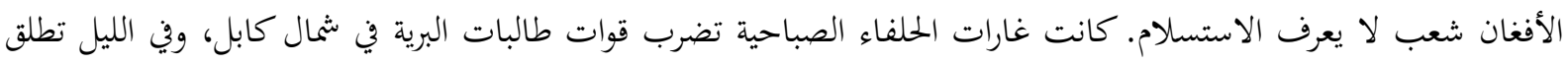

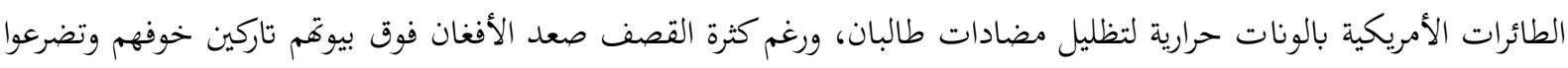

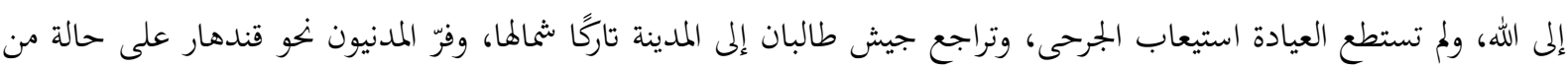

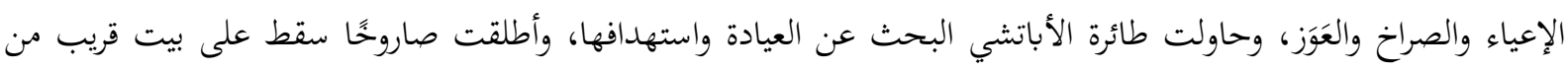

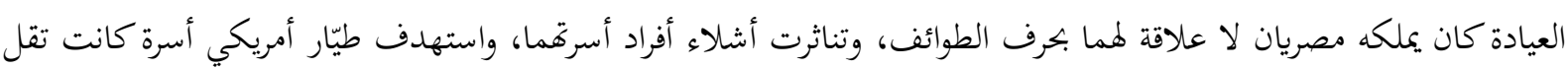

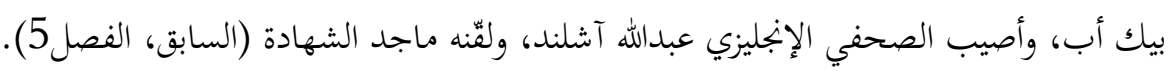
سقطت كابل في يد الحلفاء، وفقدت قيادات طالبان تواصلها، وفقد أعضاء جيش الخلاص تواصلهم أيضًا؛ لكن بقي

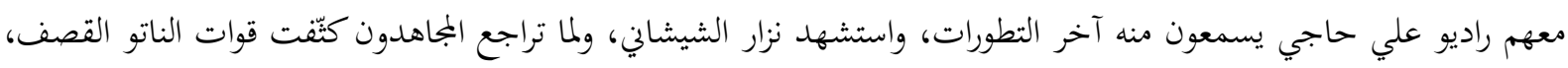

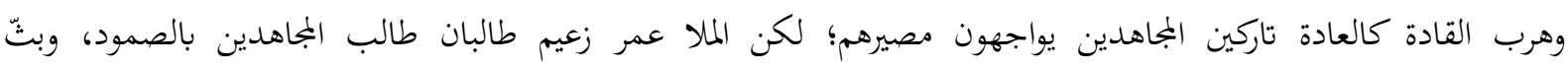

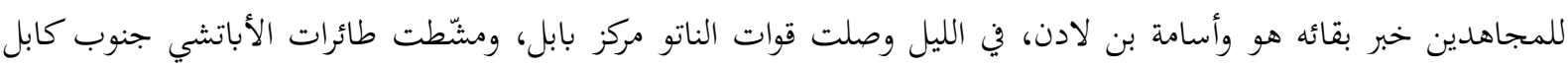

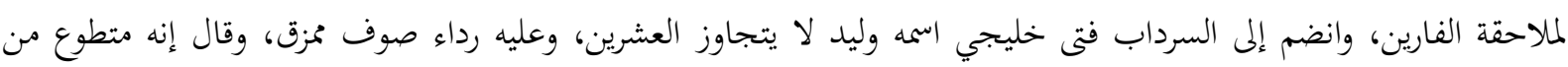

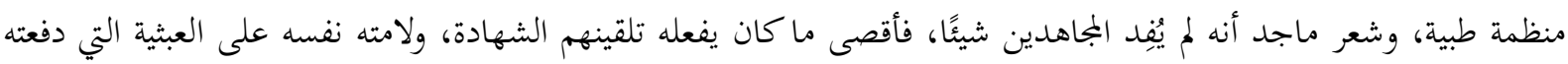

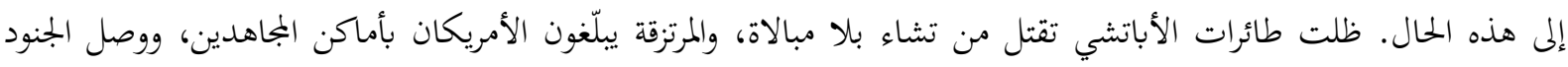


عيادة علي حاجي، لكن عليَّا حاجيَّا لم يدُلمّم على شيء، وخَشي المندسون في السرداب من أن يفتك الجنود بعلي فخرجوا، وكان

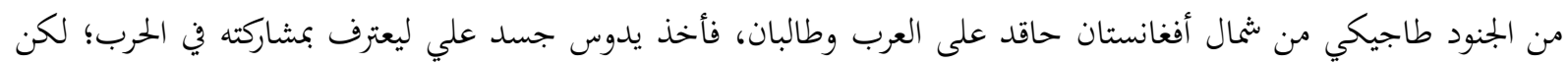

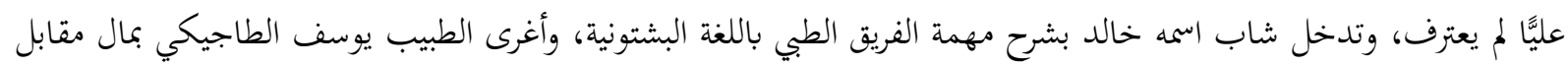

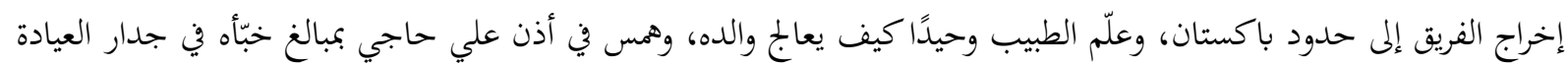

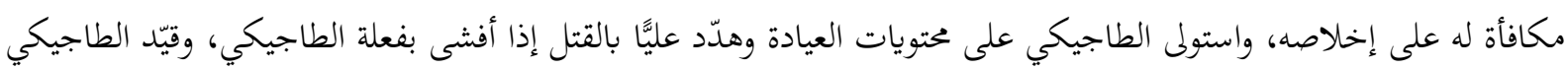

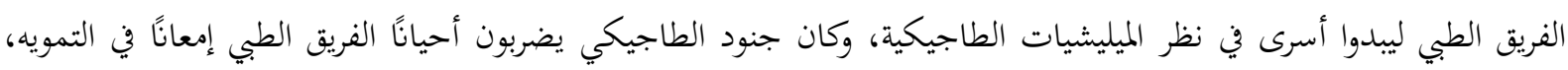

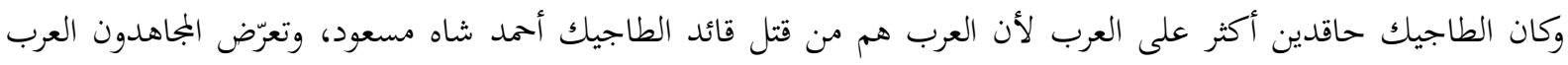

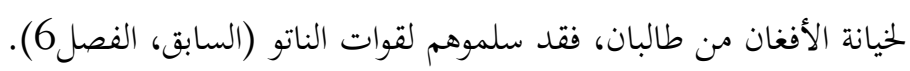
صرّح الفتى الخليجي وليد أن اسمه الحقيقي خالد، وأنه جاء للبحث عن والده المجاهد في أفغانستان بعد أن بلغهم خبر

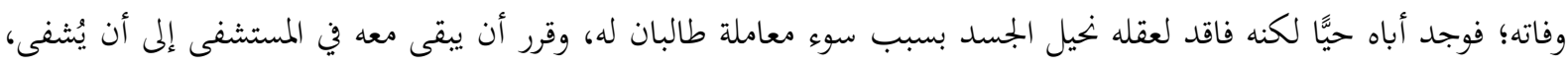

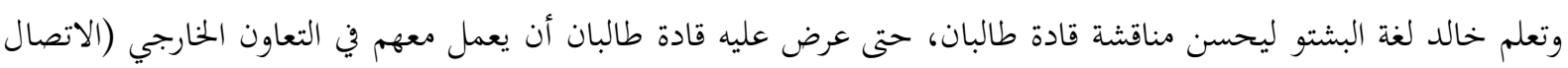

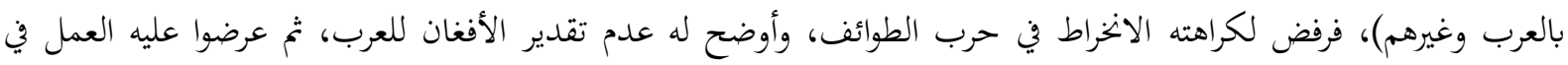

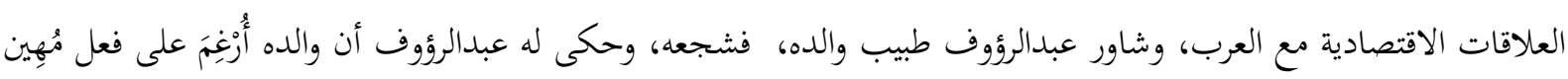

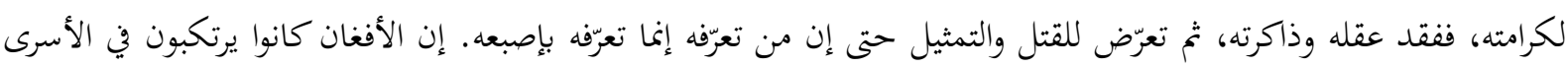

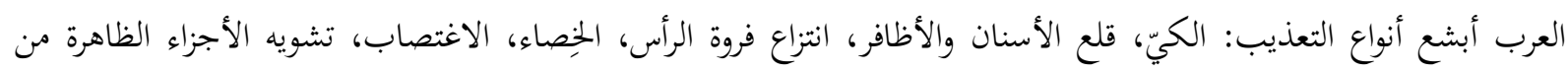

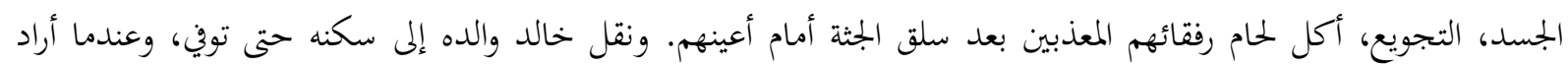
البحث عمن يساعده في غسله ودفنه قصفت قوات الناتو السكن فتحول إلى مقبرة لجثة والده (السابق، الفصل

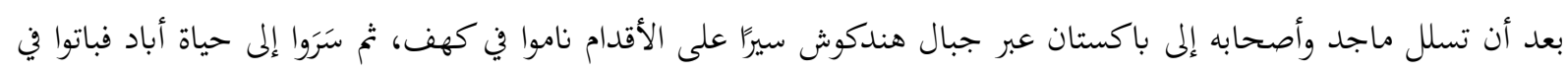

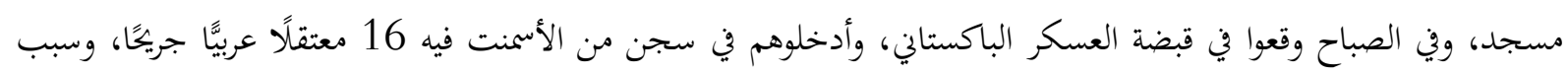

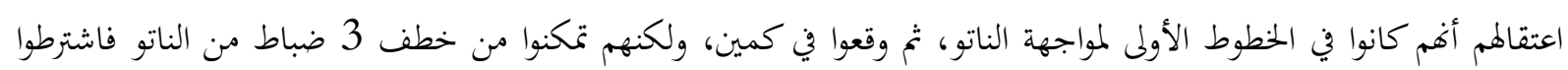

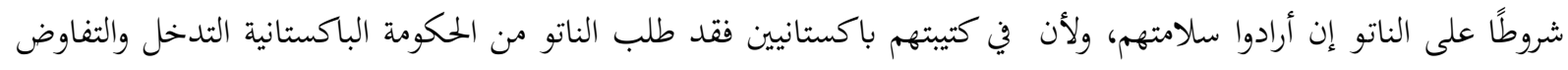

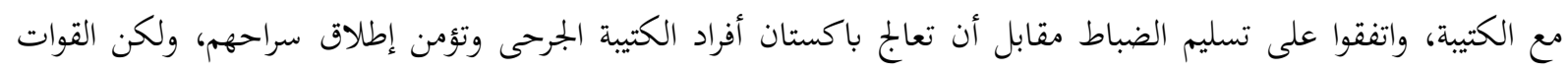

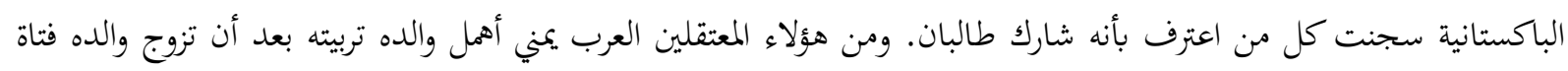

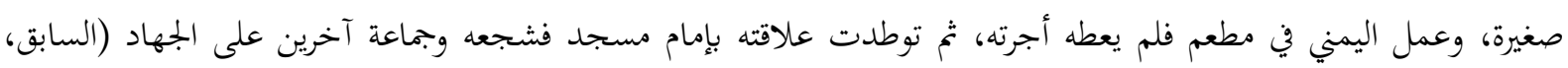

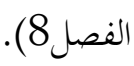

كان ياسين الفلسطيني قد لقّن ماجدًا ماذا يقول لو وقع في الأسر، فلما حقق مع الباكستانيين أخبرهم ما وصّاه به ياسين

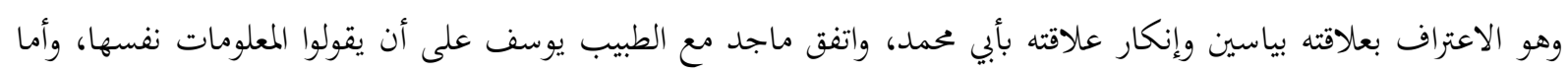

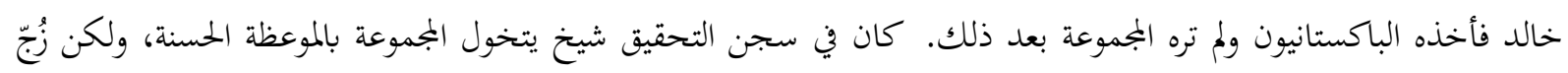

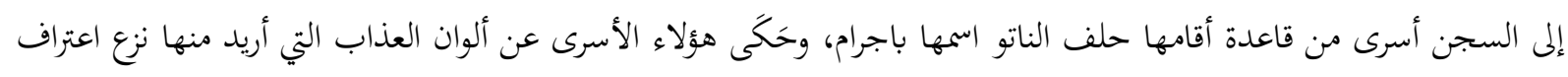

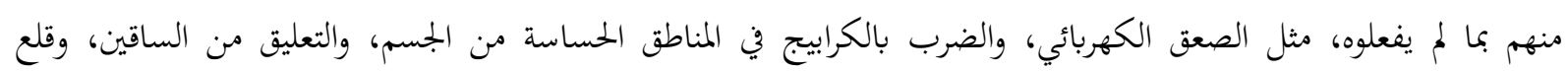

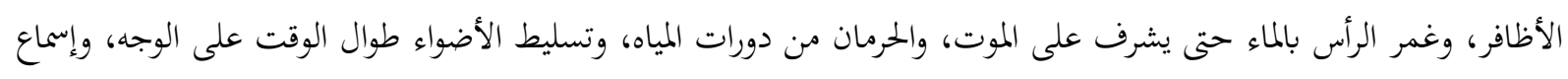

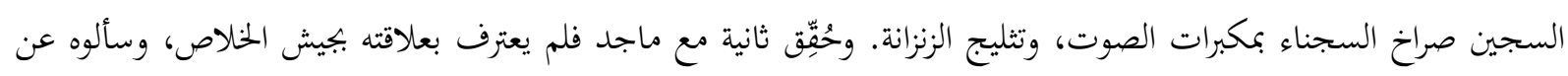

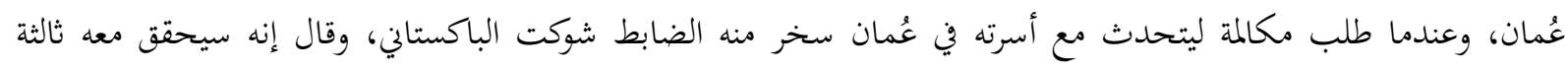

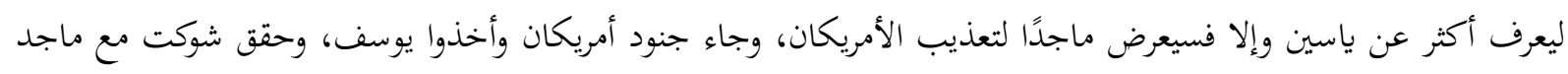


مرة ثالثة، وهدّده بأنه سيسلّمه للأمريكان بتهمة علاقته بابن لادن أو للطاجيك بتهمة أنه عربي؛ لكن ماجدًا لم يعترف بشيء جديد، وفي التحقيق الرابع حقق معه أمريكي يرتدي زي رعاة البقر اسمه سام في ردهة فيها مختلف الجنسيات، وسأله إن كان إنسان

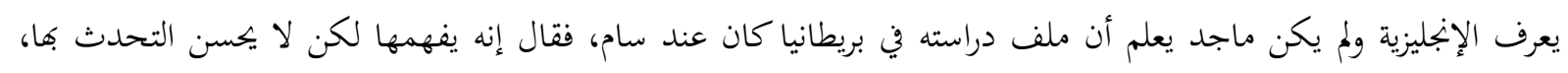

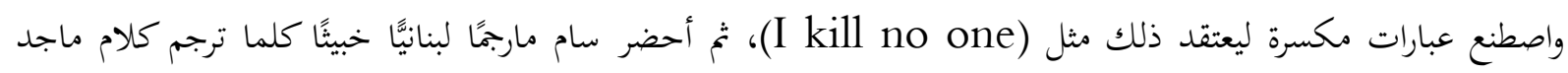
أضاف أمورًا لم يقلها ماجد، حتى تعارك معه ماجد وضحك الأمريكي، وأصر ماجد على عدم وجود ما يدينه (السابق،

أُخْرجِ ماجد من السجن، ووضع في غرفة نوم مريحة، فاغتسل، وقضى صلواته، ثم أدخل غرفة تحقيق، وظل غافيًا فيها حتى

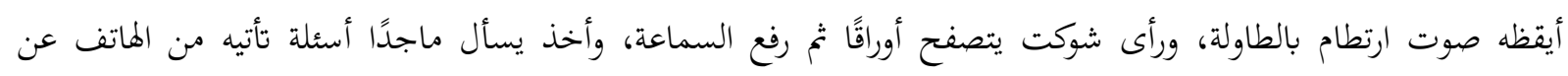

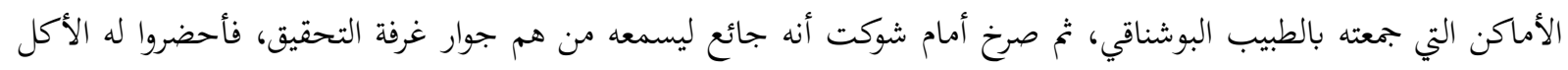

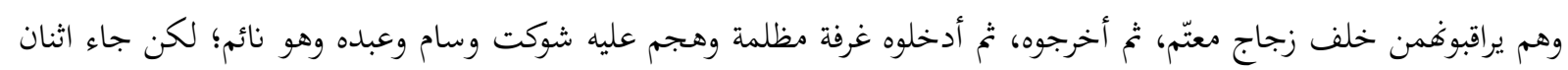

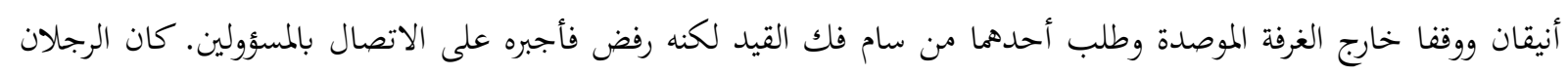

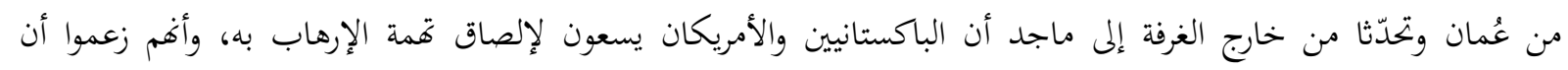

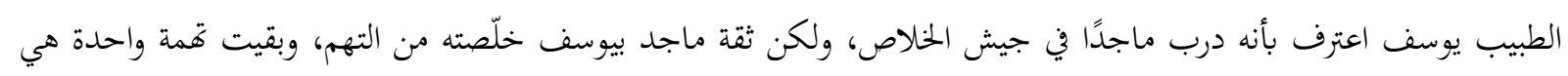

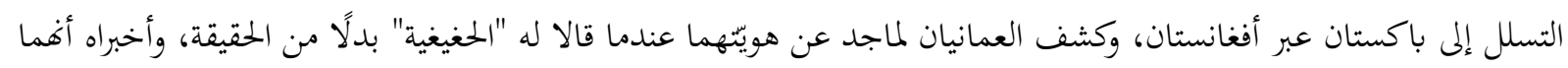

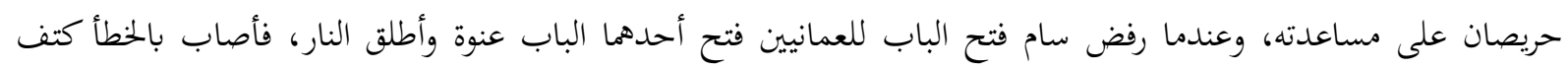

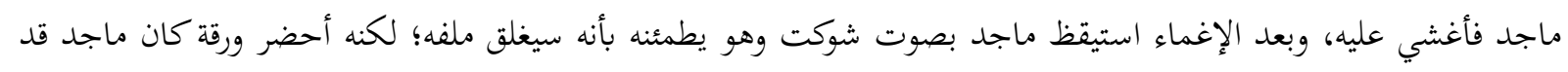

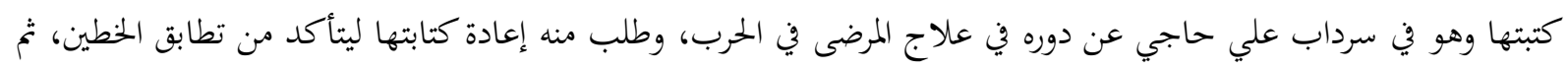

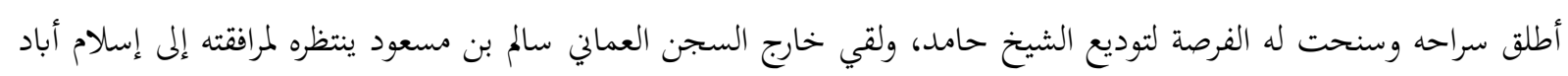

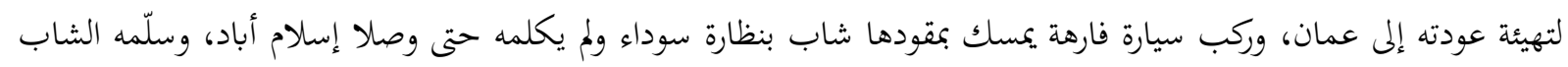

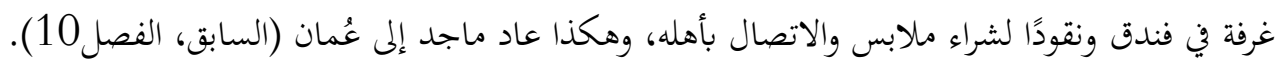




\section{المبحث الثاني: العلامات عند تشارلز بيرس وعلاقتها بالترميز:}

إن أيسر تعريف قدّمه بيرس للعلامة sign هو قوله: إفها "أيُّ شيء يُمثِّل موضوعًا [أي ينوب عنه] بأية طريقة"

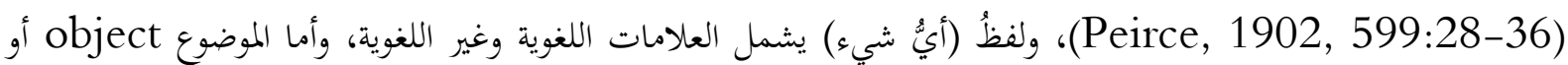
المحال إليه the denoted thing فهو ينطبق على أي شيء يمكن الحديث عنه أو التفكير فيه، سواء كان له وجود في العالم

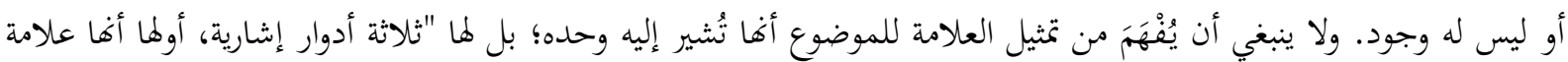

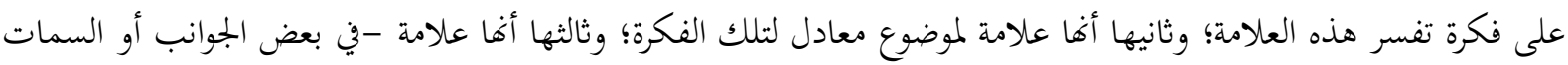
المميّزّة qualities- بحعل الفكرة على اتصال مع موضوعها" (Peirce,1868, W 2:223). Peirce,1873, W 3:66- ويُمكِننا أن نستخلص جُلّ السمات التي لا تنفك عن أية علامة من حديث بيرس

2) العلامة شيء مادِّي سواء كانت صوتَّا مسموعًا، أو كلمة مكتوبة، أو أي شيء محسوس، وتُسمَّى هذه السمة المادية بالمصطلح المنطقي "الفصل" موصوفًا بوصف "المادي: material quality. 3) أن يكون لها صلة بالموضوع الذي تشير إليه؛ حتى يتمكن الذهن من ربطها بموضوعها.

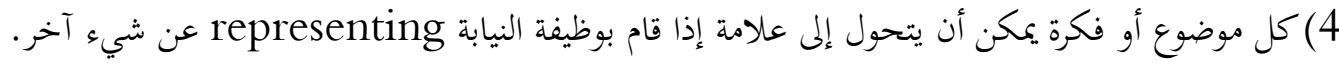

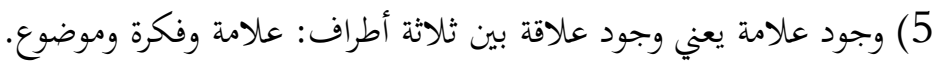

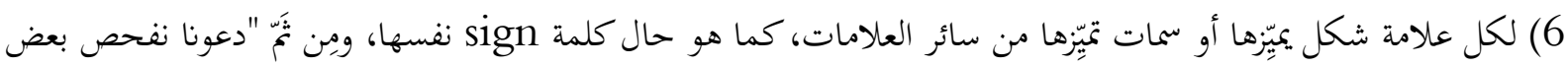
الرموز اللغوية للعلامات على العموم. يجب أن يكون للعلامة فصول [سمات] في نفسها تعمل على تمييزها، ويجب أن يكون

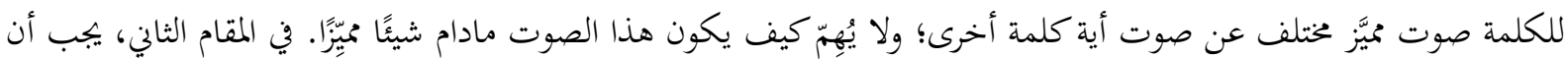

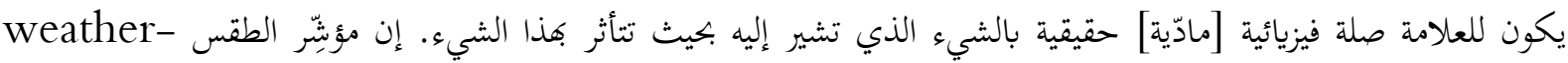

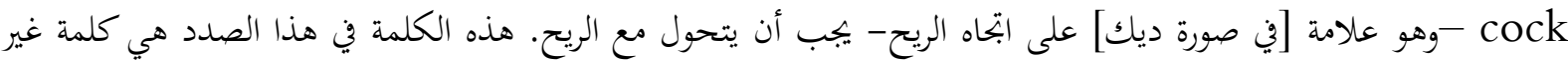

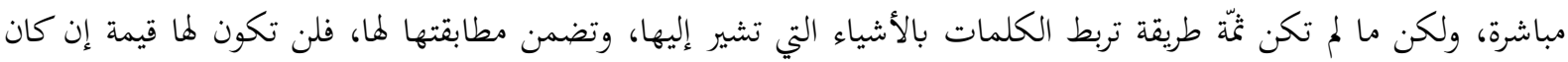

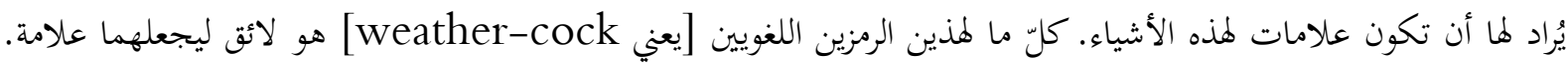

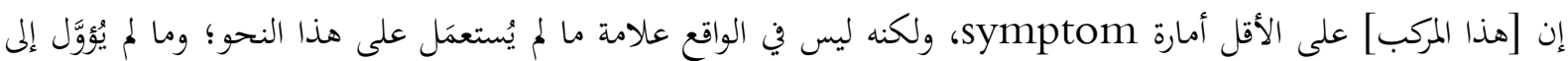
فكرة، ويعرض نفسه للمعالجة الذهنية" (Peirce,1873, W 3:76; CP 7.355). 7) العلامة تنتج الفكرة في الذهن.

\section{وثمة سمات أخرى للعلامة وردت في مواضع أخرى من أعمال بيرس، وهي:} 1) العلامة وسيط representamen لأنها تنقل المعرفة من مُبِلِّغ العلامة إلى مؤوِّها: "تستلزم العلامة أو الوسيط علاقة

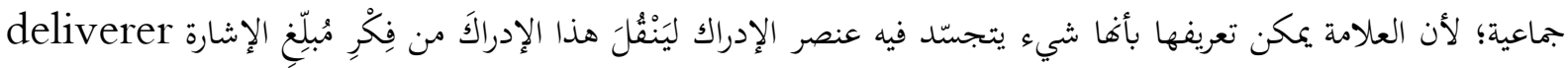

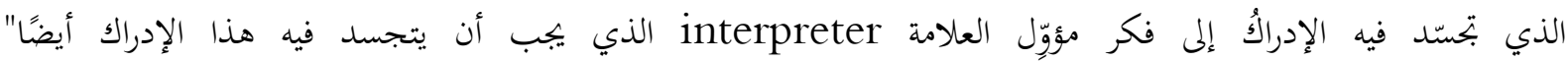
(Peirce,1895, MS [R] 16:12; PM 52) فكرة عن الموضوع: ((قد تكون لدينا مصلحة وسيطة في شيء مادام هذا الشيء ينقل إلى الذهن فكرة عن شيء آخر، ومادام يفعل ذلك فهو علامة أو وسيط" (Peirce,1894, EP 2:5; MS [R] 1009). 
2) العلامة تنوب عن الموضوع فتثير فكرته في الذهن ثم تصبح الفكرة علامة للموضوع نفسه: "العلامة شيء يعمل على نقل

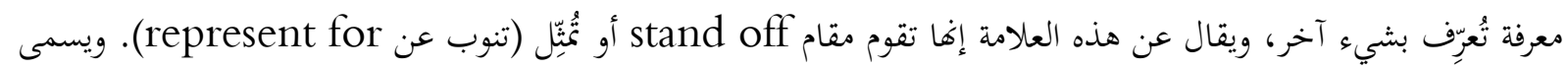
هذا الشيء الذي تنوب عنه العلامة: موضوع العلامة، أو الفكرةً التي تثيرها العلامة في الذهن، وتُعَدّ الفكرة أيضًا علامة ذهنية

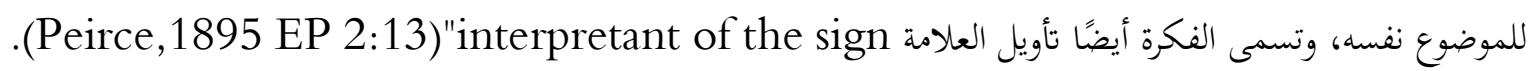

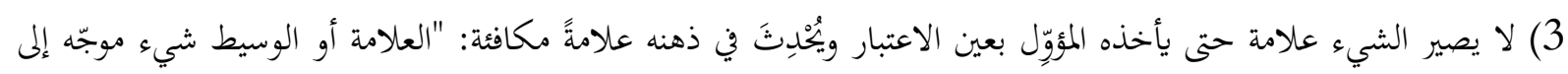

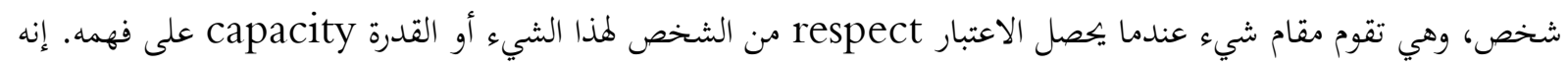

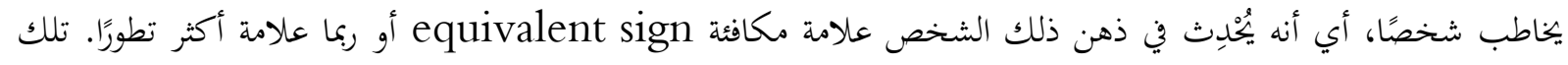

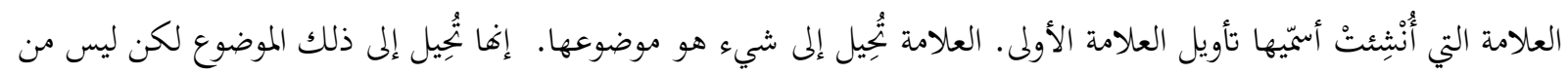

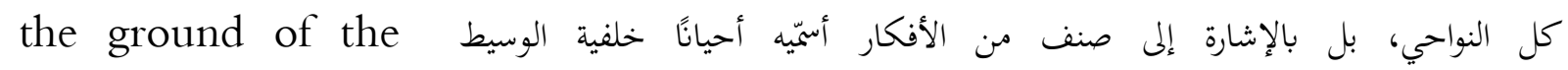
representamen

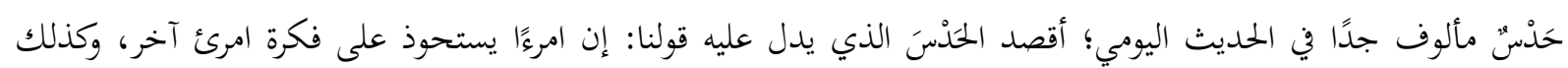

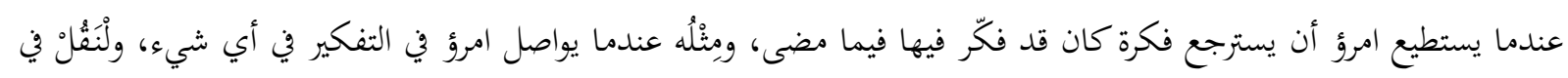

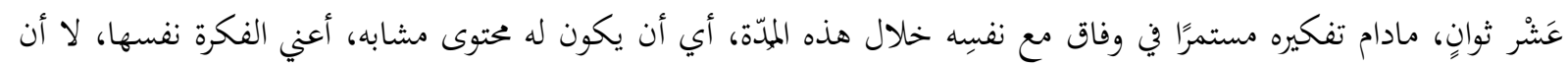
تتغير فكرته في كل لحظة زمنية فاصلة" (Peirce,1897 CP 2.228).

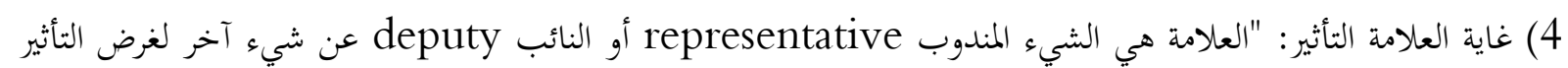
في الذهن" (Peirce,1899-1900 MS [R] 142:3).

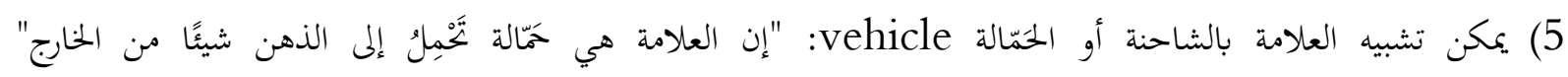
.(Peirce,1893 NEM 4:309-10; CP 1.339) 6) يمكننا أن نعبر عن وظيفة العلامة بقولنا (تُجِيل إلى موضوع)، أو (تحمل معنى)، أو (تؤدي إلى تأويل): "ذلك الذي تقوم

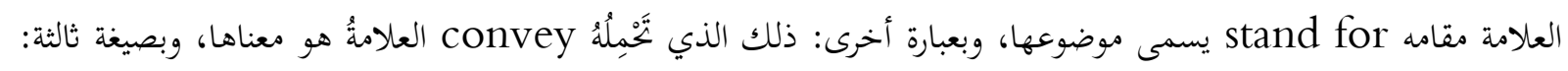
إن الفكرة التي تؤدي إليها give rise العلامةُ هي تأويلُها" (ibid). وحسب تلك السمات يمكن تيسير تعريف العلامة عند بيرس بأفا: شيء محسوس ينوب عن موضوع، ويثير في الذهن

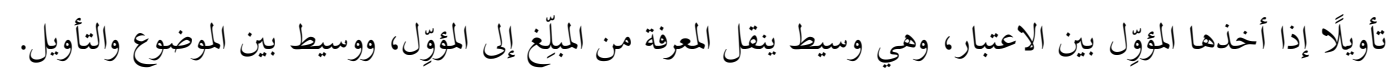

\section{الأنواع الرئيسية للعلامة بحسب أنواع الوجود:} تأتي هذه الأنواع الرئيسية نتيجة لرؤية بيرس إلى الوجود على أنى أنه ثلاثة أنواع:

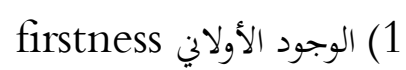
2) الوجود الثانياني (1) الوجود الالي Secondness 3) الوجود الثالثاني (لوجود النيان Thirdness

إن كل الحقائق الممكن تحقُقها قبل أن تُوجَد في الكون هي الوجود الأولاني، فإذا ظهر منها شيء في الكونِ وعالم الحقيقة

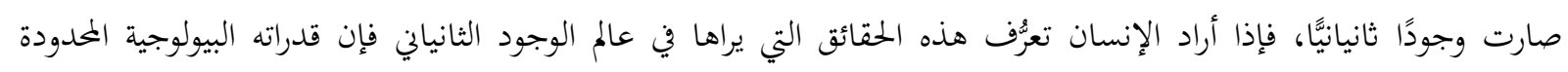

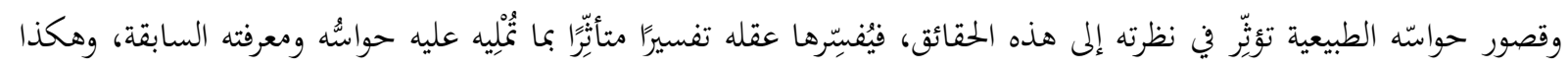

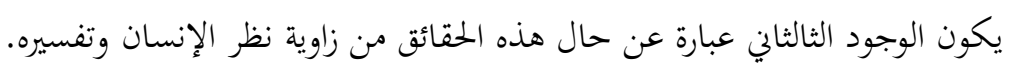


فلنأخذ مثالًا على ذلك- الألوانَ، فالألوان حقيقة كونية، فإذا استقرّ لون أحمر في كرسي أنيق صار في الوجود الثانياني، فإذا أوّله الإنسان على أنه لون ملكيّ صار في الوجود الثالثاني.

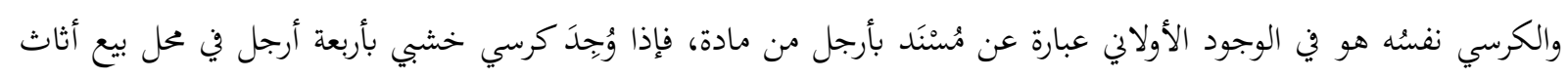

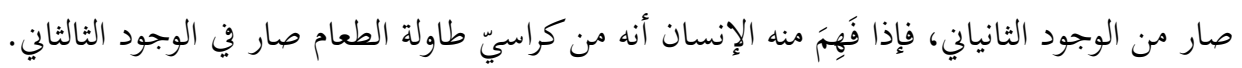

إن الإنسان في الوجود الثالثاني يجعل كل الأشياء علامات يفهم منها أمورًا أخرى، وهذا ما يسمّيه بيرس التمثيل أو النيابة

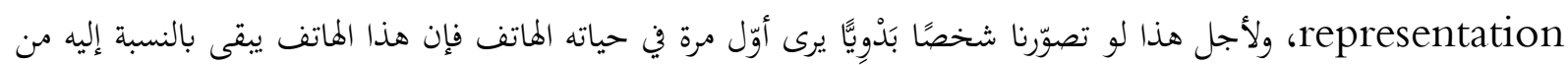

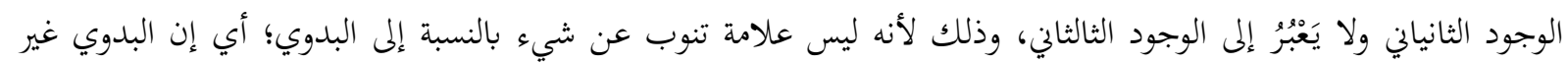
قادر على أن يفهم من هذا الهاتف شيئًا.

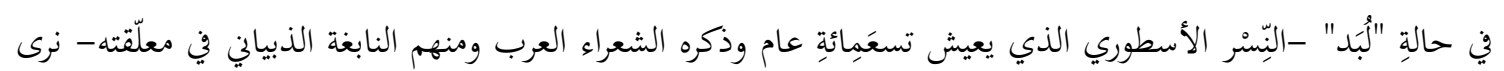

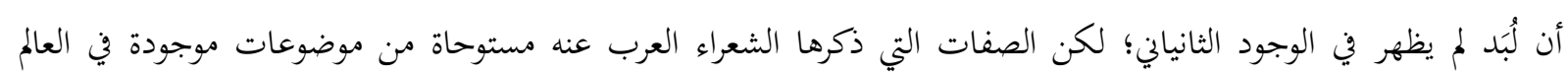

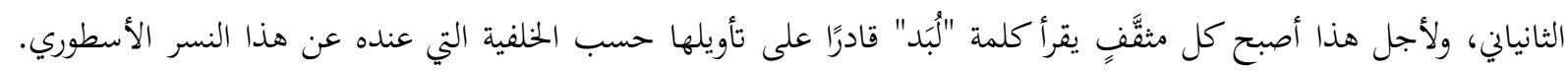

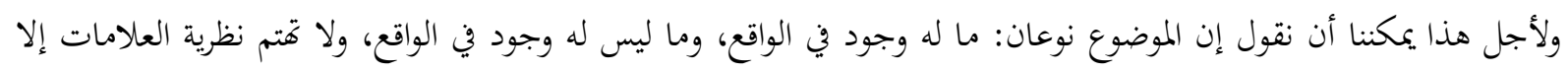

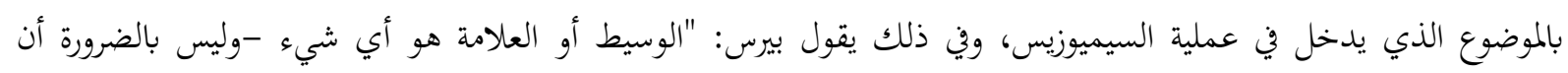

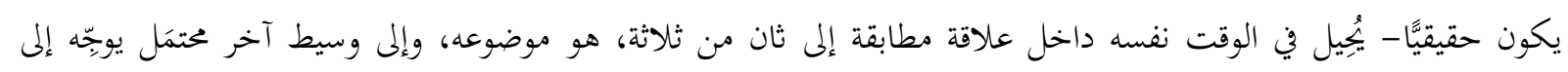

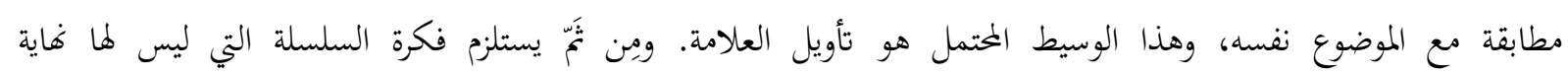
مكنة"(Peirce, 1902 MS [R] 1147).

يقول بيرس عن الأنواع الثلاثة الرئيسية للعلامات النابتحة عن أنواع الوجود: "ثمّة ثالوث مهم للغاية هو أن هناك ثلاثة أنواع

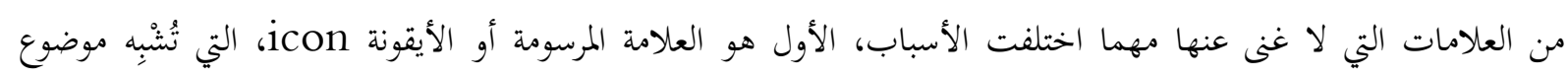

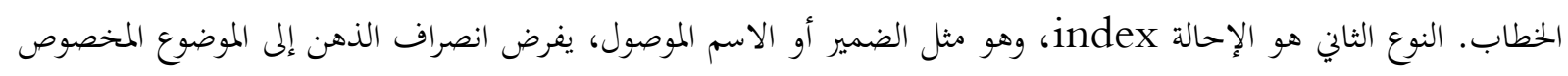

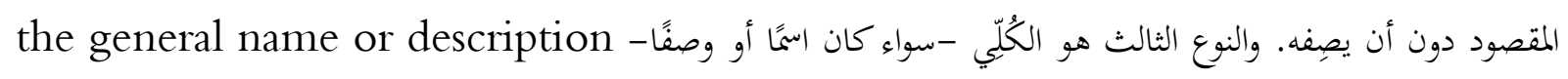

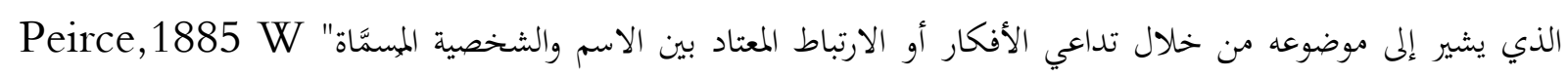

إن الأيقونة icon أو العلامة المرسومة the diagrammatic sign هي العلامة التي تماثل أو تشابه المشار إليه نخو

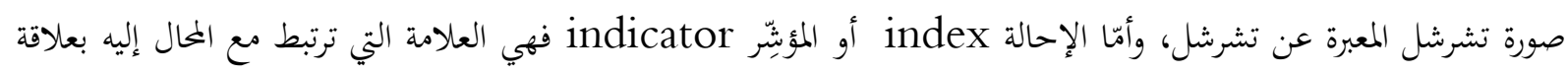

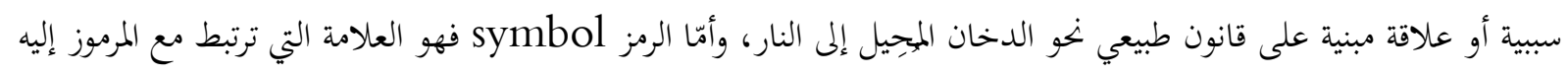

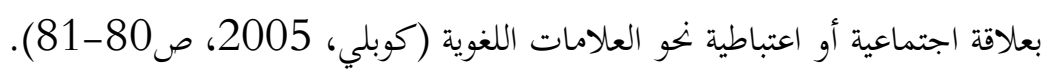
وتتفاوت أنواع العلامة الثلاثة الرئيسية في درجة قدرتا على الاستغناء عن العنصرين الآخرَيِِْ اللذين يشكِّلان مع العلامة

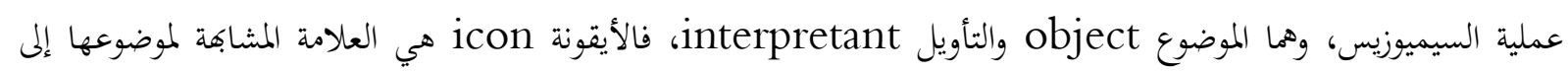

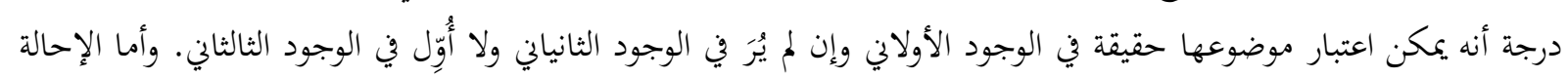
index

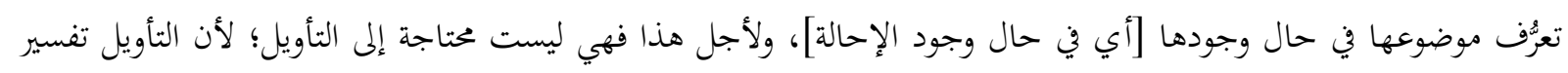

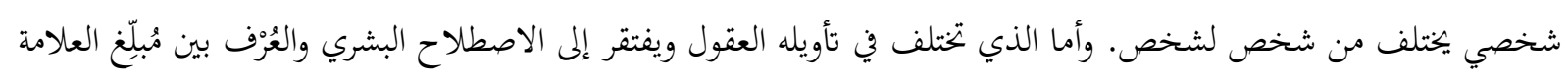
interpreter فهو النوع الأخير من العلامات Symbol deliverer 
ثلاثة أنواع، الأول هو الأيقونة، وهي تمثل موضوعها تمثيلًا مُغنِيًا بهكم خِصِيصة virtue تمتلكها حتى لو كان الموضوع وعملية

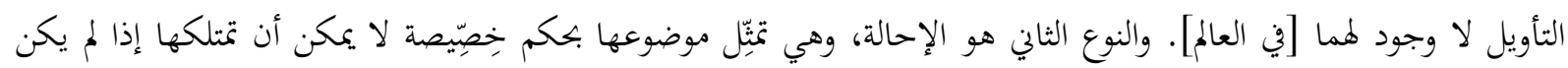

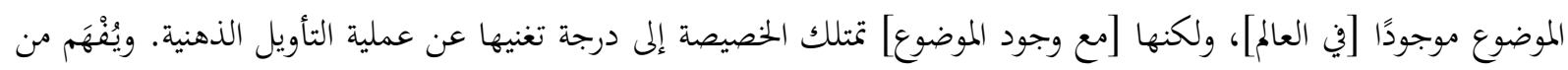

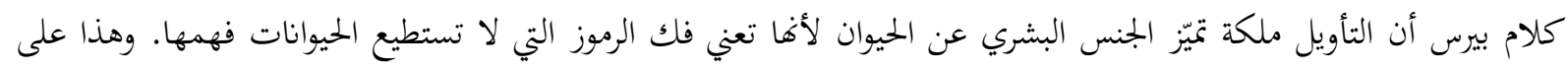

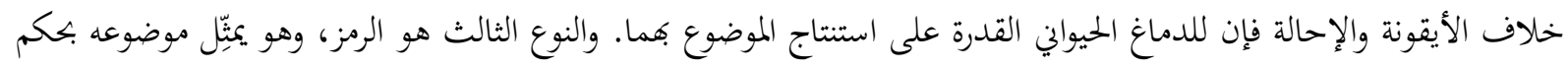

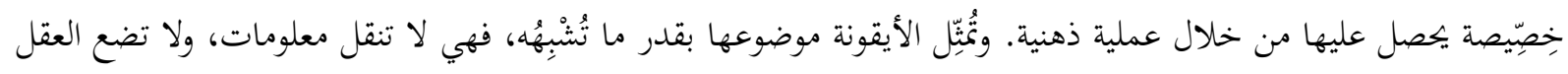

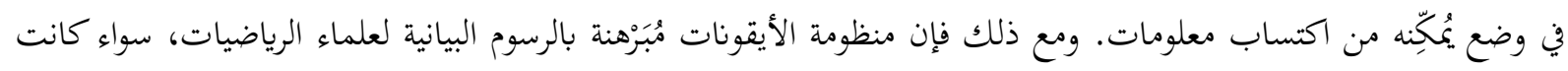

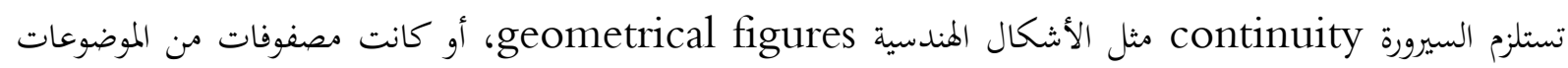
المنفصلة arrays of discrete objects مثل مجموعة من الصيغ الجبرية algebraical formulae، فكلها أيقونات. إن الأيقونات لابد أن تُستعمل في أية عملية تفكير)(Peirce,1900 MS [R] 142:3-4). من الواضح تأثير المفاهيم المنطقية والفلسفية في تقسيم العلامات وفق أنواع الوجود، فقد ربطها بيرس بفكرة الأجناس

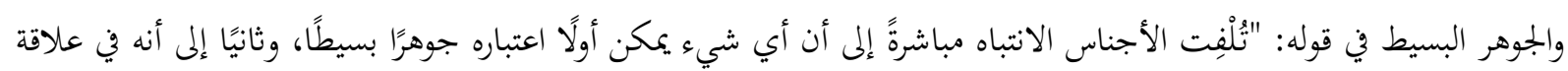

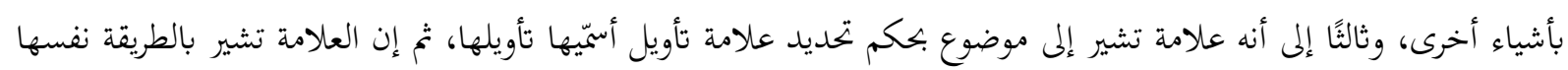

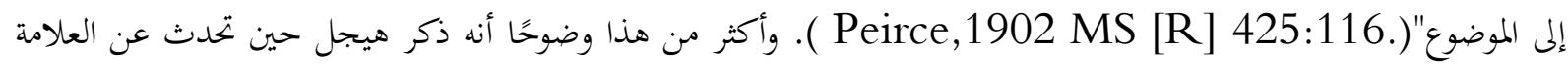

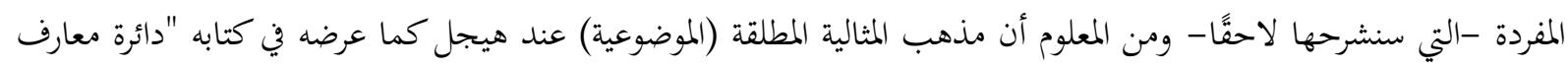
العلوم الفلسفية" يرى أن كل الظواهر الطبيعية والاجتماعية تقوم على أساس المطلق (الروح والعقل أو الفكرة المطلقة أو عقل العالم

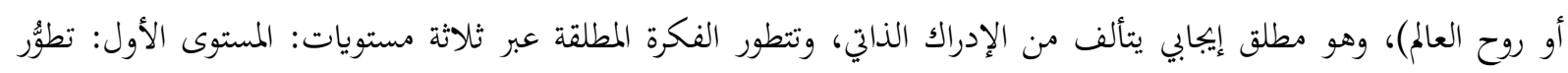

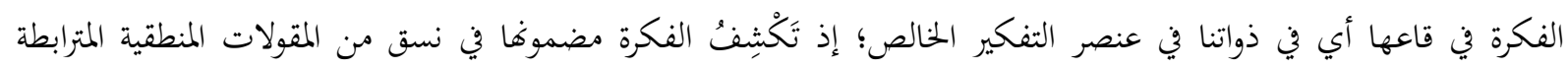

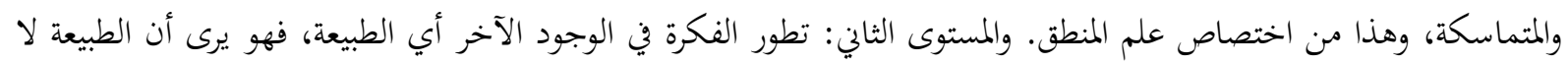

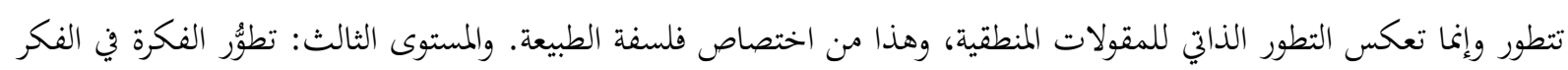

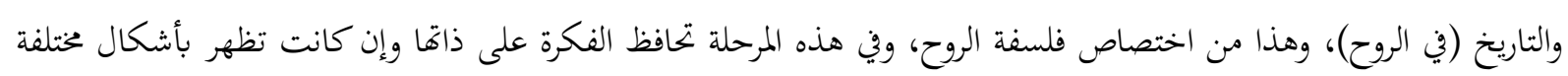

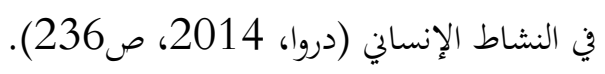

نفهم من الأقسام الرئيسية للعلامة -التي ذكرناها سابقًا - أها أقسام لا تخلو منها أية علامة، فكل علامة لابد أن تكون

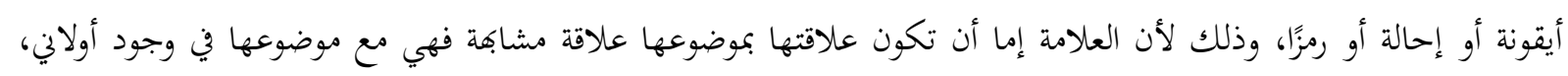

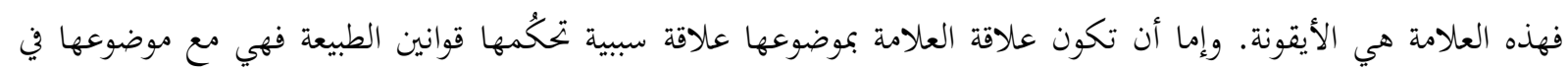

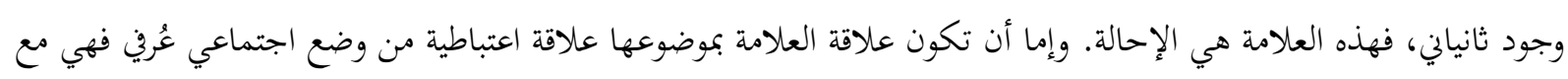
موضوعها في وجود ثالثاني، فهذه العلامة هي الرمز .

قسّم بيرس الموضوع إلى موضوع مباشر Immediate Object (الموضوع الذي ثُتِيل إليه العلامة قبل أن تُعيَّد بتأويل

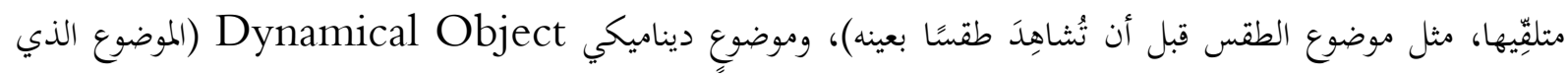

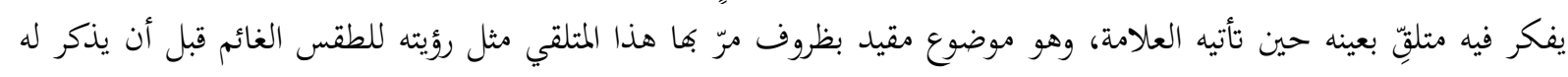

أحد كلمة الطقس) (Peirce, 1909, a site).

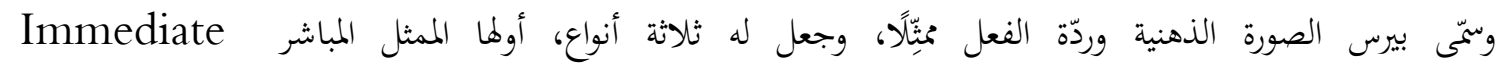

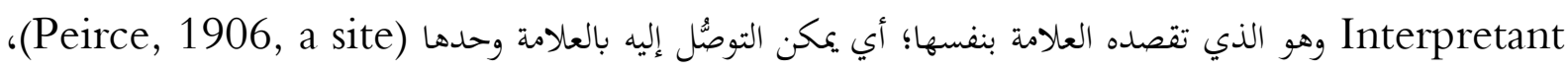




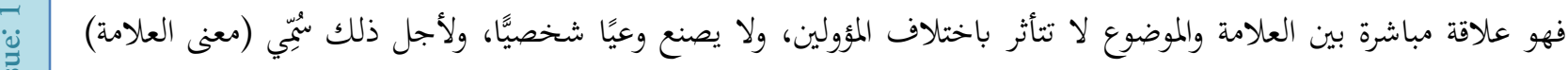

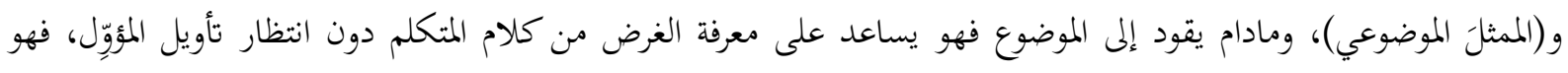

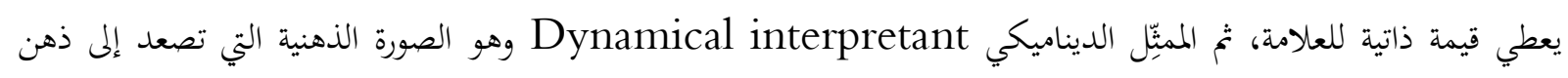

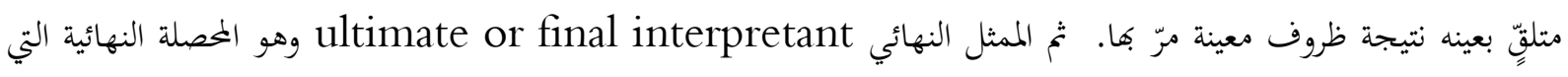

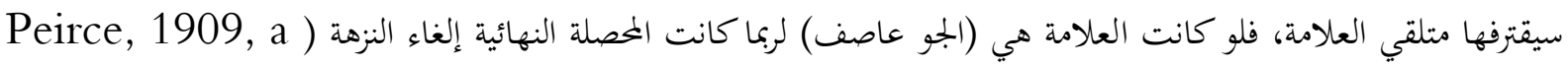
(site 


\section{المبحث الثالث: سمات الترميز وبُنَاها في رواية شهادة من زمن الحرب: السمة الأولى: الترميز عبر العلامات اللغوية والعلامات غير اللغوية:}

من خلال المبحث السابق عرفنا أن العلامة عند بيرس (شيء ينوب عن موضوع، ويثير في الذهن تأويلاً إذا أخذها المؤوِّل

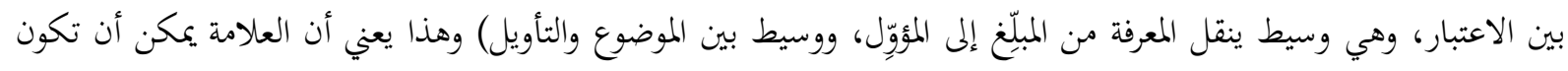

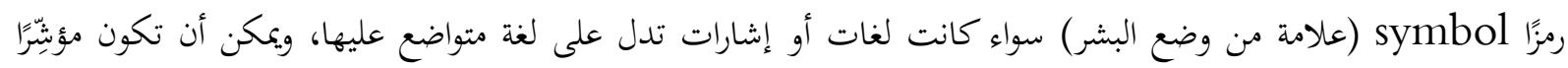

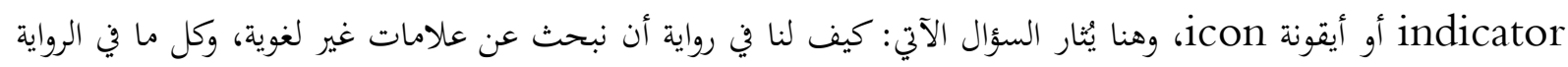

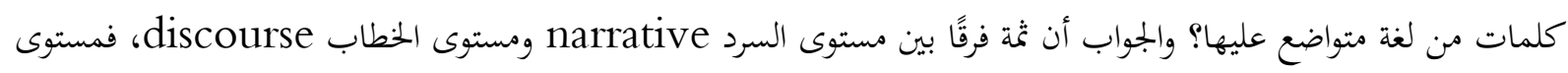

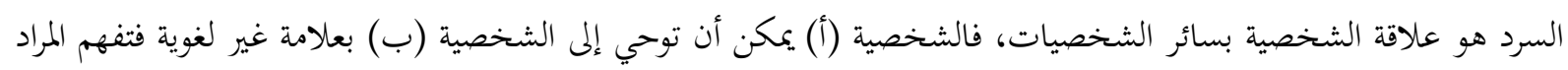

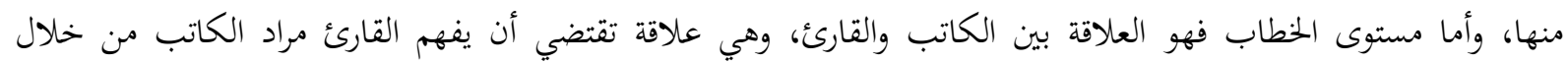
علامات لغوية فقط هي الكلمات والجمل المسطرّة في روايته.

فمن أمثلة العلامات اللغوية التي جرت بين الشخصيات ما سمعه ماجد من "قفشات أبو سليم اللبناني (صاحب المقهى)

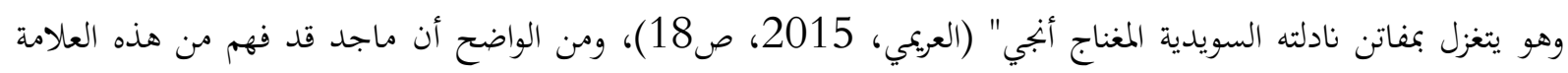

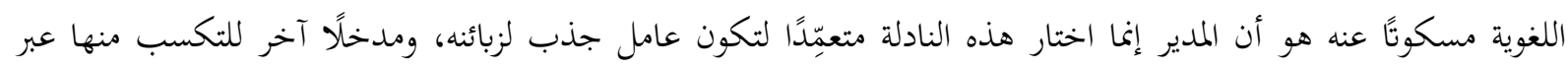

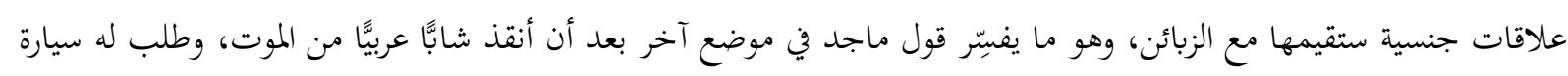

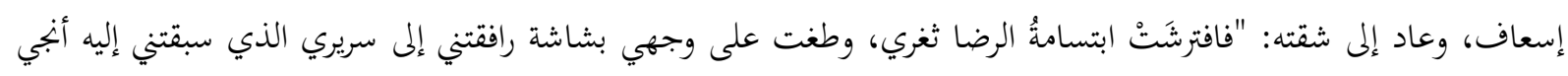

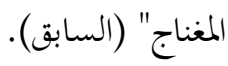

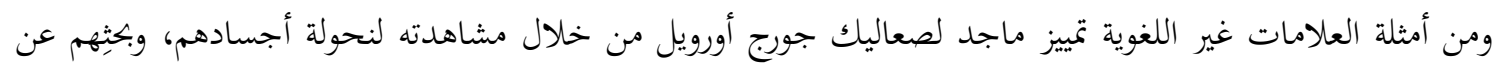

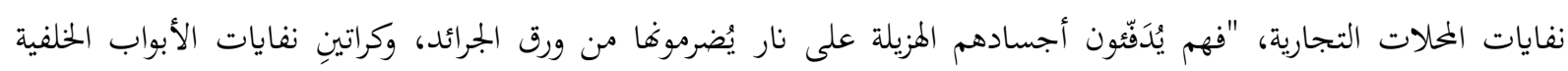
للمحلات التجارية" (السابق)، فهذا السلوك منهم غير اللغوي كان علامة غير لغوية قادته إلى معنى اقتضائي هو اعتبارهم صعاليك.

إن التبئير الداخلي الذي أسنده محمد العريكي إلى شخصية ماجد جعل تأويل العلامات اللغوية وغير اللغوية في روايته إنما

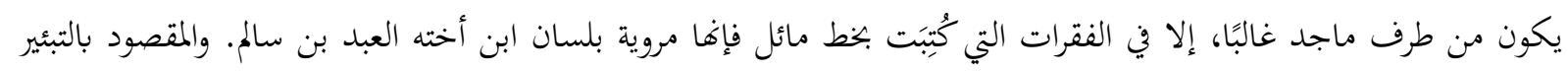

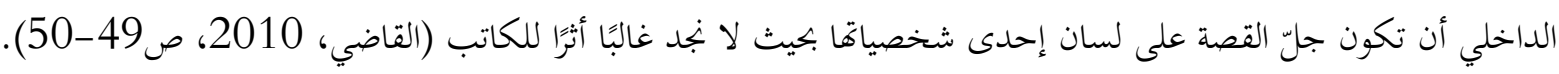
السمة الثانية: تحوّل الأفكار إلى علامات تؤدي وظيفة الترميز: الأصل أن العلامة - كما يذكر بيرس- شيء مادي سواء كانت صوتًا مسموعًا، أو كلمة مكتوبة، أو أي شيء محسوس،

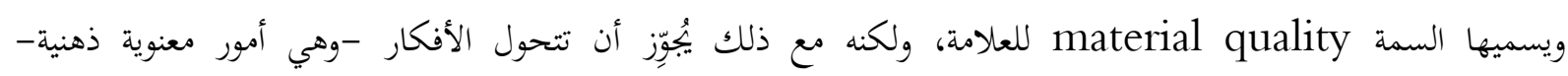

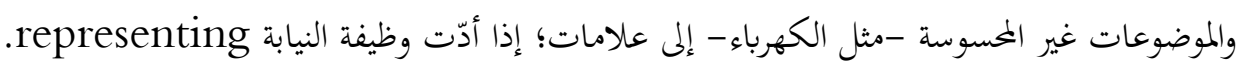
بعد إعلان الرئيس الأمريكي بوش الابن الحرب على الإرهاب وأفغانستان صارح ياسين ماجدًا بأنه ينتمي إلى جمعية خيرية

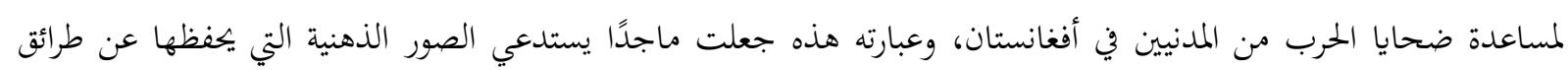

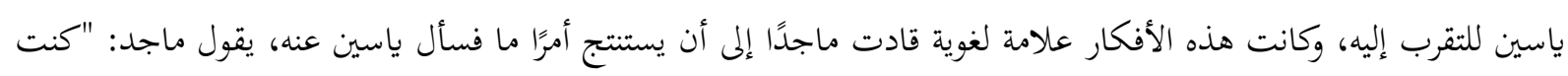

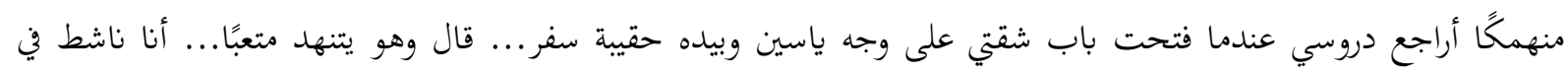

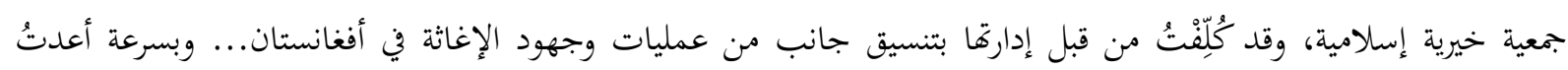


شريط علاقتي بياسين منذ بداية تعريف عليه، وسعيه للتقرب مني أكثر دون أصدقائه الثلاثة، فسألته: هل مهمتك المكلف بها لدعوة

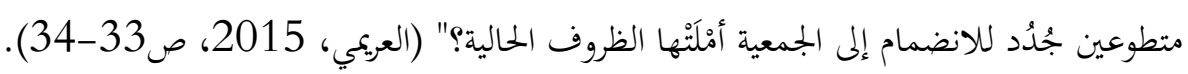
وكاد ماجد أن يرفض الانجراف خلف دعوة ياسين لولا أن الأفكار مرت أخرى دفعته إلى استنتاج إيجابي نحو نوايا ياسين:

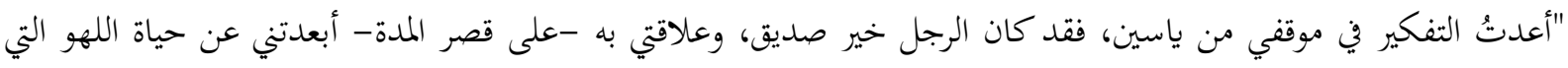

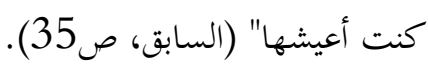

والواضح من هذه الأمثلة أن تحوّل الفكرة إلى علامة في الرواية ترمز إلى معنى اقتضائي إنما يجصل في مواضع المونولوج النفسي حين تخلو الشخصية بنفسها أو ينتقل صوتا من مخاطبة العالم الخارجي إلى محاورة ذاتما.

\section{السمة الثالثة: تأويل العلامة مرهون بالمعرفة المشتركة بين المبلِّغ والمؤوِّل:}

يذكر بيرس أن العلامة وسيط depresentamen ينقل إدراكًا من مُبلِِّغِها deliverer ئلى مؤٍِّ

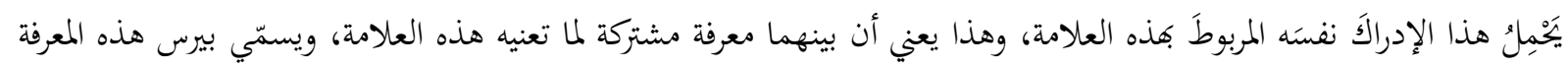

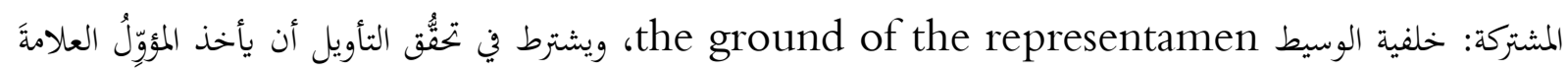

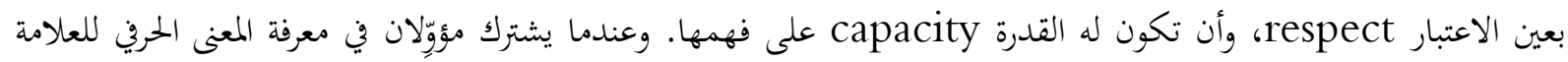
لكن أحدهما هو القادر على فهم معناها الاقتضائي بسبب الخلفية المعرفية التي بينه وبين المبلِّغ - تتولد عملية الترميز. إن الطبيعة العسكرية لهذه الرواية، ومشاهدها الحربية، وطرائقها الاستخباراتية- جعلها أرضًا خصبة للرموز التي لا يفهمها

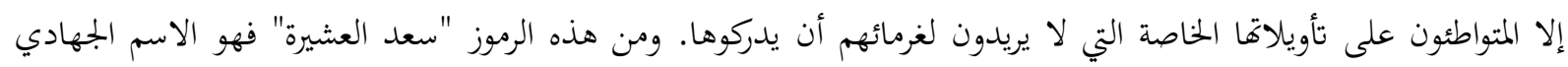

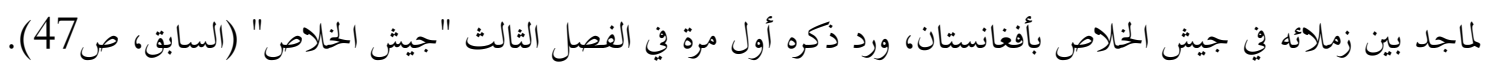
بعدما قِيدَ ماجد مكبّاً بأغلال اليدين والقدمين بوساطة سام الأمريكي وشوكت الباكستاني وعبده اللبناني أدخلوه على

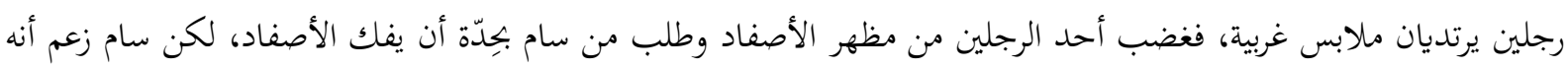

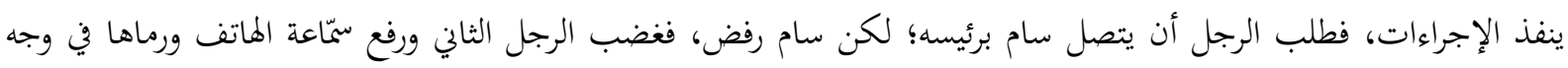

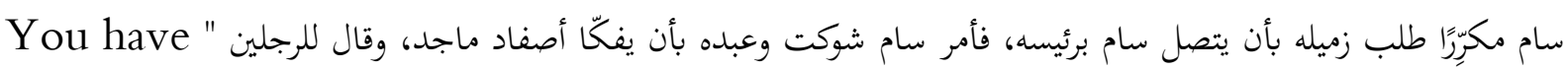

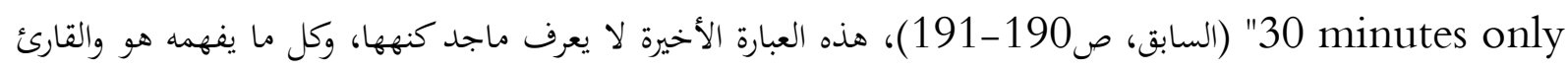

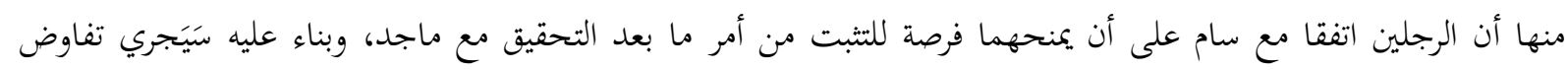

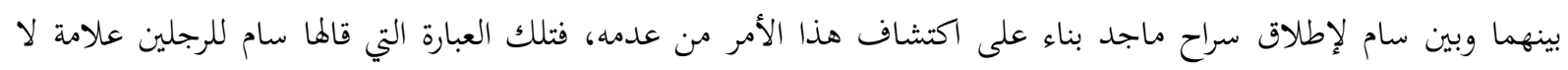

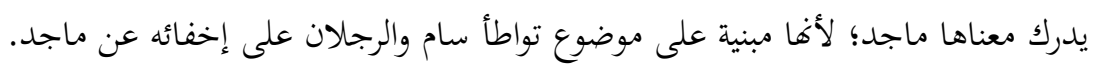

\section{السمة الرابعة: تفاوت الأنواع الرئيسية للعلامة في قدراتما الترميزية:}

حسب تقسيم بيرس للعلامة من حيث أنواع الوجود إلى أيقونة ومؤشر ورمز يتضح أن كل الناس قادرون على فهم الأيقونة لأهما

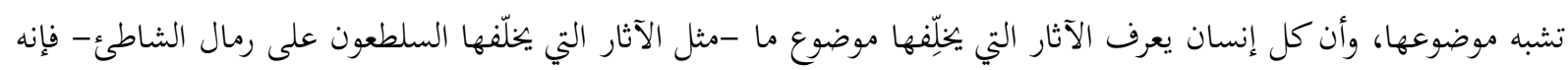

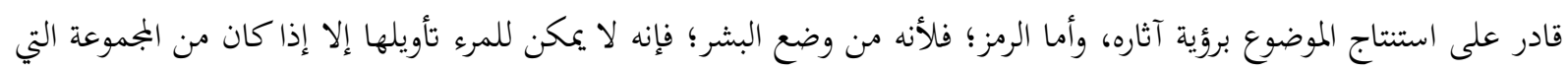
تواطأت على دلالة الرمز على مفهوم معين. والسؤال المهم المتعلق بالترميز: هل يمكن أن نجد من كل نوع من أنواع العلامات الرئيسية ما يؤدي دور الترميز أي الإحالة

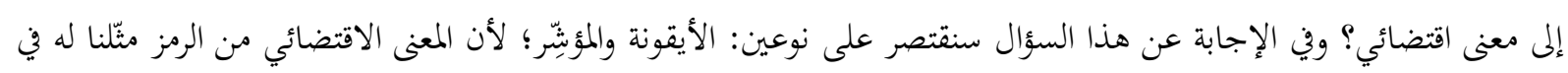


ومن المؤشِّرات الترميزية الواردة في الرواية الشقة الفاخرة التي كان يسكنها ماجد في أحد المجامع السكنية، فقد استتتجت

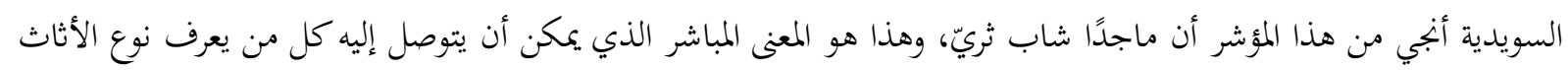

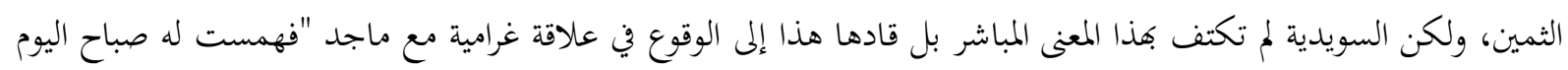

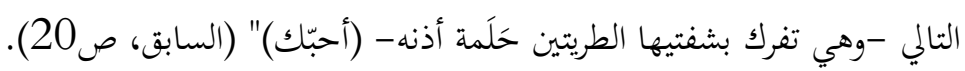

ومن الأيقونات الترميزية العربات المموِهة التي وضعها جيش الخلاص في شمال كابل، وخارطة كابل التي رُبسم فيها خط أحمر

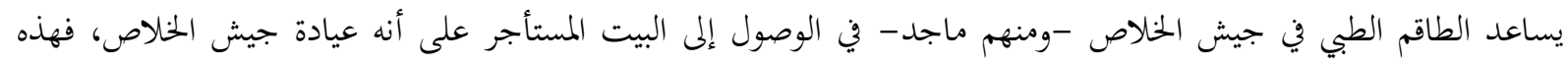

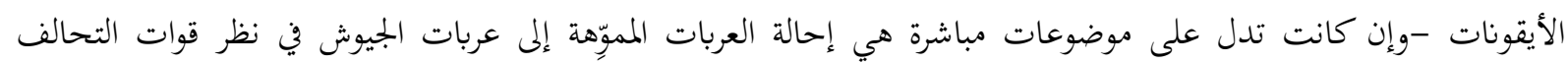

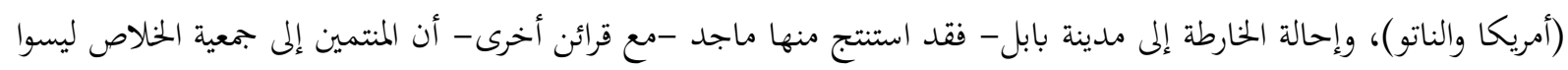

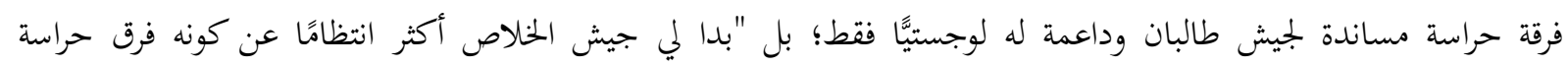

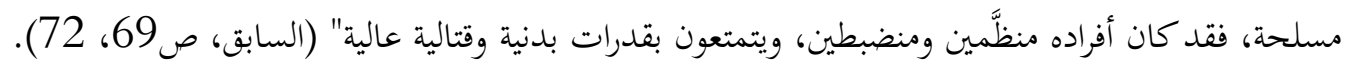

\section{السمة الخامسة: المباشر والديناميكي والنهائي:}

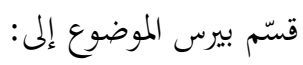

1. موضوع مباشر Immediate Object هو الموضوع قبل ربطه بموقف معين رآه مؤوِل معين، وموضوعٍ ديناميكي Dynamical Object

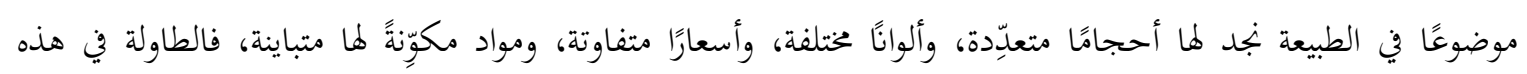

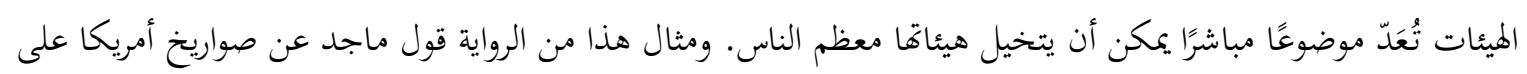

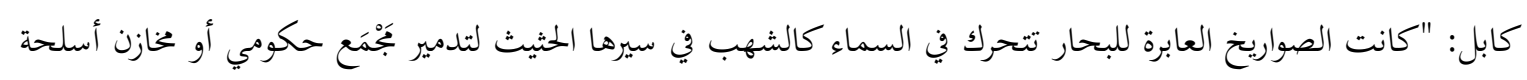

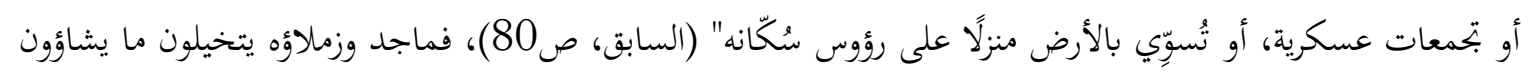

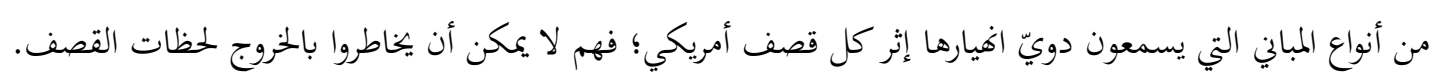

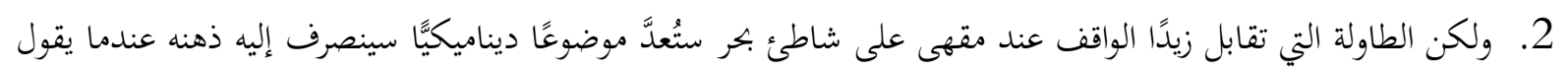

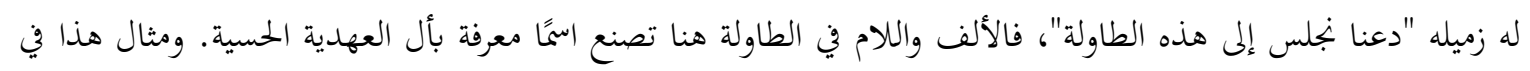

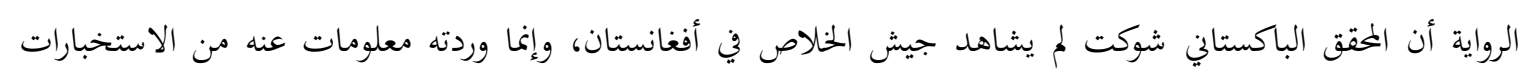

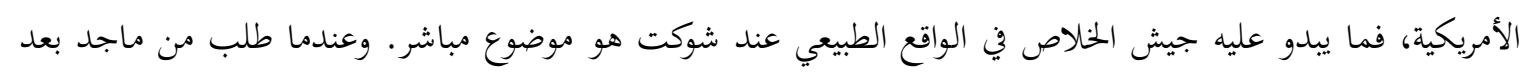

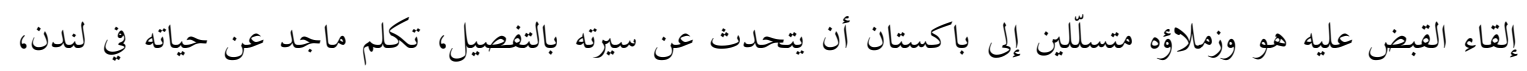

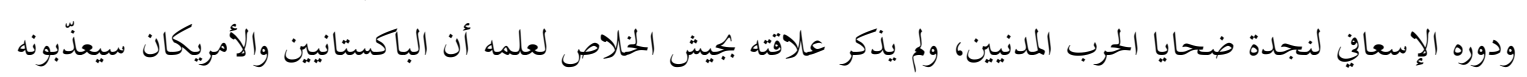

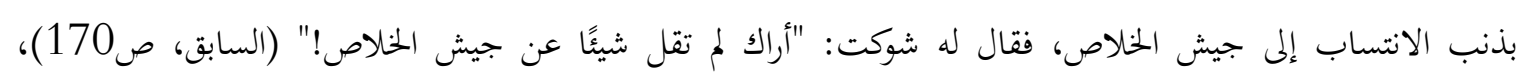

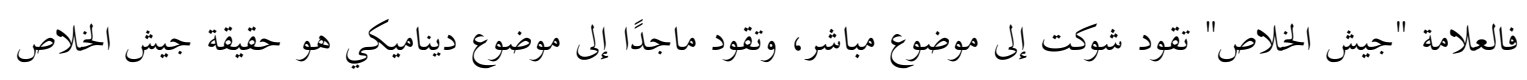
في أرض الواقع.

\section{وقسّم بيرس التأويل من حيث علاقته بالمعنيين الحرفي والاقتضائي إلى:}

1. تأويل مباشر هو الصورة الذهنية لجنس الشيء قبل رؤيته على أرض الواقع.

2. وتأويل ديناميكي هو الصورة الذهنية عن الشيء بعد رؤيته في أرض الواقع، فالمؤوِل بعيد عن هذا الشع الشيء الشئ الآن لكن

$$
\text { صورته الذهنية تحتفظ بتفصيلاته. }
$$

$$
\text { 3. و تأويل فائي، هو ردة فعل المخاطب بعد أن يستمع أو يرى علامة الشيء. بندئه }
$$


ويمكن التمثيل لهذه الأنواع بأن صورة جيش الخلاص في ذهن شوكت هي تأويل مباشر، وصورة الجيش في ذهن ماجد تأويل ديناميكي، وردة فعل ماجد -وهي إنكار علاقته بجيش الخلاص - بعد أن سأله شوكت عن جيش الخلاص هي تأويل فائي.

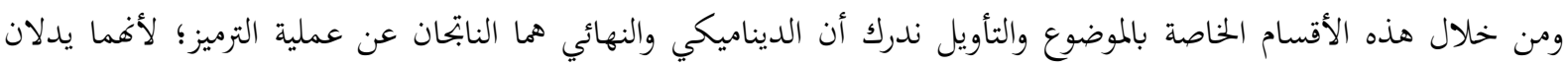

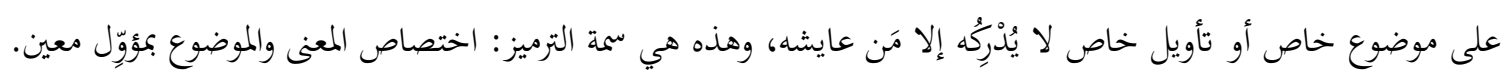




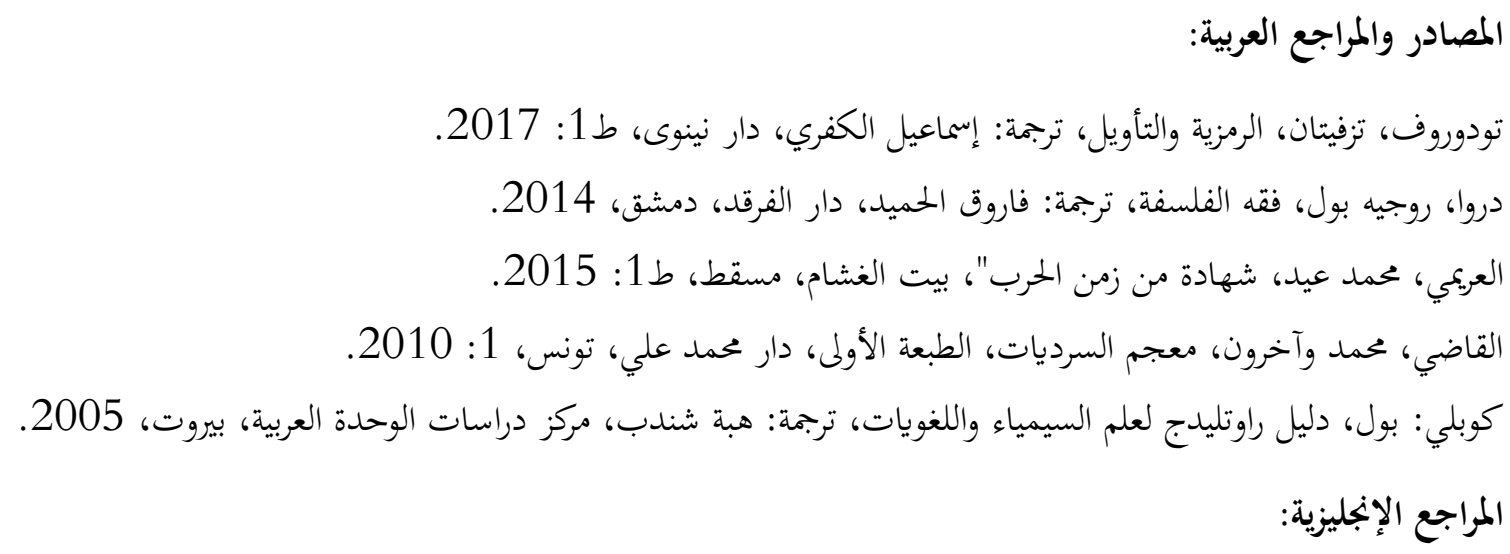

First: Charles Sanders Peirce researches within the site "Stanford Encyclopedia of philosophy Peirce's theory of signs":

1868 | Some Consequences of Four Incapacities | W 2:223.

1873 | On the nature of signs | W 3:66-8.

1873 | Logic. Chap. 5th | W 3:76; CP 7.355-6.

1885 | One, Two, Three: Fundamental Categories of Thought and of Nature | W 5:243.

1894 | The Art of Reasoning. Chapter II. What is a Sign? | EP 2:5; MS [R] 1009.

1895 [c.] | On the Logic of Quantity, and especially of Infinity | MS [R] 16:12; PM 52.

1895 | Short Logic: Chapter I. Of Reasoning in General | EP 2:13.

1897 [c.] | On Signs [R] | CP 2.228.

1893-5 [c.] | Chapter II: The Categories | NEM 4:309-10; CP 1.339

1899-1900 [c.] | Notes on Topical Geometry | MS [R] 142:3.

1901-1902 [c.] | Definitions for Baldwin's Dictionary [R] | MS [R] 1147

1902 [c.] | Reason's Rules | MS [R] 599:28-36, within the site.

1902 | Minute Logic: Chapter I. Intended Characters of this Treatise | MS [R] 425:116.

Second: Charles Sanders Peirce researches within the site "iass-ais.org/the-commensdictionary-of-peirces-terms":

Letters to William James, 1909.

On the system of existential graphs considered as instrument for the investigation of logic, 1906. 